\title{
TESTIMONIOS RELIGIOSOS DE LA PRESENCIA FENICIA EN ANDALUCÍA OCCIDENTAL ${ }^{1}$
}

\section{RELIGIOUS TESTIMONIES OF THE PHOENICIAN PRESENCE IN WESTERN ANDALUCÍA}

\author{
por \\ MARÍA BELÉN \\ JOSÉ LUIS ESCACENA ${ }^{2}$
}

RESUMEN Las últimas investigaciones sobre la paleodesembocadura del Guadalquivir y enfoques teóricos nuevos permiten dibujar un renovado panorama de la implantación fenicia en la zona. Aquí se analiza este hecho histórico desde la valoración de una serie de elementos religiosos que pueden asignarse a los grupos orientales afincados en la región.

\begin{abstract}
Recent paleogeographical researchs and new methodological approaches offer a renovated panorama of Phoenician colonization in the Lower Guadalquivir. This work takes a view on the valuation of some religious materials that might be attributed to oriental population settled in the region.
\end{abstract}

\section{INTRODUCCIÓN}

Una serie de trabajos arqueológicos recientes que ahora sería prolijo enumerar, y que afectan a las costas meridionales hispanas desde Alicante al menos hasta la desembocadura del Tajo, están empezando a cambiar poco a poco el panorama que teníamos de la colonización fenicia en la Península Ibérica. Por una parte, los estudios paleogeográficos del denominado "Proyecto Costa", abordado por el Instituto Arqueológico Alemán, vienen dibujando un litoral para el primer milenio a.C. en gran medida distinto al que hoy conocemos, de manera que tierras que en la actualidad se consideran interiores no lo fueron tanto en tiempos protohistóricos (Arteaga y Roos 1995; Arteaga y otros 1995; Schulz 1995) (mapa 1). Por otra, nuevos

1. Este trabajo fue publicado en su primera versión en Actas del Congreso "El Mediterráneo en la Antigüedad: Oriente y Occidente" (Cunchillos y otros, eds.), Sapanu. Publicaciones en Internet II (1998) [http://www.labherm.filol.csic.es].

2. Los autores son profesores del Departamento de Prehistoria y Arqueología de la Universidad de Sevilla. 
planteamientos teóricos y metodológicos acerca del concepto de aculturación (Rivera 1975; Gruzinski y Rouveret 1976; González Wagner 1983 y 1986; Alvar 1990, 1991 y 1993), así como de las huellas arqueológicas que la interacción cultural origina (Belén y Escacena 1995), han producido hipótesis de trabajo que buscan contrastación en los muchos datos que las actividades arqueológicas de campo vienen acumulando en Andalucía, especialmente en las dos últimas décadas.

El objetivo de nuestro trabajo es doble. Primero queremos presentar de nuevo-por tratarse de hallazgos recientes poco divulgados- el conjunto arqueológico documentado en una intervención de urgencia en la casa-palacio del Marqués de Saltillo, en Carmona, que constituye uno de los últimos aportes de la arqueología protohistórica bajoandaluza al conocimiento de la religiosidad de las comunidades que habitaban la zona en época tartésica (Belén y otros 1997). De otro lado, y a raíz de algunas investigaciones sobre el intercambio cultural entre fenicios e indígenas que desde hace unos años llevamos a cabo en el Bajo Guadalquivir, queremos retomar en parte las interpretaciones que hasta ahora se han ofrecido del yacimiento del Carambolo. A la luz de los nuevos enfoques teóricos a los que aludíamos anteriormente, las características singulares de dicho yacimiento y la riqueza de muchos de sus materiales arqueológicos sugieren explicaciones históricas que tienen que ver muy directamente con los intereses de la implantación fenicia en la zona y con el papel que en esta colonización tuvieron algunos santuarios erigidos en sitios clave para el comercio entre Oriente y Occidente.

Desde estas líneas introductorias debemos insistir de nuevo, y de forma muy especial, en que nuestras propuestas deben explicarse en un marco paleogeográfico diferente del actual, que hacía de Carmona, por ejemplo, un enclave situado a menos de una jornada de distancia de la costa a través del camino que, desde la desembocadura del río Guadaira en el Golfo tartésico, conducía al reborde de Los Alcores ${ }^{3}$. Por otra parte, sólo un enfoque metodológico distinto al tradicionalmente empleado para distinguir los asentamientos fenicios de los que no lo fueron, y que tenía como única referencia las pequeñas colonias del litoral mediterráneo andaluz (Pellicer y otros 1977), podría permitirnos empezar a aceptar unos nuevos modelos de la ocupación semita al Oeste del Estrecho de Gibraltar, cambio de posiciones que tiene su ejemplo paradigmático en el sitio gaditano del Castillo de Doña Blanca, que ha pasado en pocos años de considerarse un enclave autóctono de la población tartésica a una auténtica colonia fenicia que hoy disputa a Cádiz el haber sido solar fundacional del establecimiento legendario de $\mathrm{Gadir}^{4}$.

\section{UN SANTUARIO URBANO EN CARMONA}

La comarca de los Alcores, próxima a Sevilla capital, debe su fisonomía y su nombre a una cadena de cerros de formación terciaria, que se levantan hasta por encima de los doscientos metros s.n.m., entre las terrazas del Guadalquivir y las vegas de los ríos Corbones y Guadaira. Su potencial agropecuario y, sobre todo, su situación en relación con las comunicaciones entre la costa y el interior del Guadalquivir, convirtieron esta región natural en uno de los principales focos de la Andalucía tartésica, como ya pusieron de manifiesto a fines del siglo pasado los trabajos de J. Bonsor (1899).

Desde sendos enclaves situados sobre las mesetas elevadas de Carmona, al norte, y Mesa de Gandul, al Sur, dotados de sólidas defensas, se controlaba un amplio territorio, muy próximo a la antigua línea de costa como acabamos de señalar, por el que discurrían las principales arterias de comunicación del valle, tanto fluviales como terrestres.

3. Cálculos estimados a partir de Ruiz-Gálvez 1992.

4. El Profesor Ruiz Mata ha expuesto en distintos foros científicos los argumentos que le llevan a defender esta polémica hipótesis. 
Las intervenciones arqueológicas que desde mediados de la década de los ochenta se vienen sucediendo en el recinto histórico de Carmona, no han hecho más que corroborar la gran influencia que en su desarrollo posterior tuvo la pronta incorporación de la ciudad a los circuitos comerciales de ámbito mediterráneo. Distintos investigadores han señalado la presencia de artesanos, comerciantes o agricultores fenicios en esta población. Nosotros, partidarios también de la cohabitación de orientales y tartesios en Carmona, ofrecemos para su discusión los argumentos que nos han llevado a defender el hallazgo de un complejo cultual vinculado a la comunidad foránea establecida aquí al menos a partir del siglo VII a.C.

\subsection{Los hallazgos y su contexto}

En mayo de 1992 los arqueólogos municipales de Carmona realizaron una intervención de urgencia en un solar situado en lugar céntrico y elevado del actual barrio de San Blas, junto a la iglesia del mismo nombre, que en su tiempo albergaba las cuadras y otros servicios de la residencia palaciega del Marqués del Saltillo, y excavaron un complejo de estructuras pertenecientes a distintas fases de edificación superpuestas. Tres de estos edificios construidos uno sobre otro, siempre con la misma orientación, se fechan entre la segunda mitad del VII, o principios del VI, y mediados del siglo V a.C. Todos ellos acusan una fuerte influencia de las técnicas constructivas de tradición fenicia, claras, sobre todo, en las formas de enlucir paredes y suelos 5 .

La fase más reciente, anterior a mediados del siglo $\mathrm{V}$, es la que está documentada en mayor extensión. A ella corresponden una serie de dependencias contiguas, que ocupan longitudinalmente de NE a SO toda la zona excavada, pertenecientes a un mismo edificio, que consta, al menos, de un amplio espacio enlosado, que suponemos un patio abierto, y tres habitaciones de 3,40, 5,10 y 6,60 m., en sentido NE-SO. La más pequeña y la mayor tenían un pavimento arcilloso de color rojo fuerte, de $4-5 \mathrm{cms}$. de espesor, en tanto que la habitación central estaba solada con adobes. Adosados en ambos casos al muro oriental de las respectivas estancias, medianero con las contiguas, se documentó un banco de mampostería en la habitación mayor, y un hogar rectangular, también de adobes, en la central y mediana.

A pesar de que el depósito arqueológico correspondiente a esta fase constructiva resultó muy afectado por las obras de nivelación del terreno realizadas con máquinas, se recuperaron abundantes materiales que reseñamos sucintamente. Sobre el pavimento de losas se hallaron numerosos fragmentos de ánforas con los que hemos podido reconstruir, en parte, ocho ejemplares, de formas diferentes. Unas conservan todavía el hombro carenado de los prototipos fenicios más antiguos (R-1 o Trayamar 1), pero tienen ya el borde que caracteriza a las producciones locales a partir de la segunda mitad del siglo VI a.C.; otras responden a la forma conocida por los especialistas como Mañá/Pascual A-4. Además de las ánforas, se documentaron, sobre todo, cuencos en forma de casquete esférico, algunos con paredes carenadas, decorados con franjas o bandas de tonos rojizos.

En los depósitos relacionados con las restantes estructuras del mismo complejo constructivo se recuperaron, junto a cuencos y vasos cerrados con decoración pintada, piezas de profundidad media, boca abierta y cuerpo de perfil en "S", que se han descrito por distintos autores como "vasos para beber", vasos en forma de tulipa o caliciformes. Muchos de estos recipientes tienen el borde recortado intencionadamente.

En cuanto al más antiguo de estos tres complejos superpuestos, en el que de forma más directa se apoya la argumentación de nuestra hipótesis, sólo pudo excavarse completa una habitación de 4,40 por 1,80 m., orientada de NE a SO en sentido longitudinal. Tenía paredes de adobes encaladas y pavimento de tierra batida pintado de rojo, y se accedía a ella desde otra estancia contigua por un vano situado en la esquina sur (fig. 1).

5. La descripción pormenorizada de la excavación puede consultarse en Belén y otros 1997. 
En tres de las esquinas de esta dependencia se excavaron sendos huecos de forma irregular en los cuales suponemos que se encajaron de pie otros tantos pithoi con decoración figurada que se recogieron fragmentados y esparcidos sobre el suelo de la habitación, junto con dos copas de cerámica gris a torno y un plato de engobe rojo que pudieron servirles de tapaderas, dos vasos para almacenar hechos a mano y un juego de cuatro cucharas de marfil talladas en forma de patas de cuadrúpedo ungulado, que corresponden a los cuartos delanteros y traseros de un mismo animal. La languidez de las pezuñas sugiere que dichas extremidades se representaron ya muertas, pues no se reproducen en posición de apoyo. Igualmente, parece que las incisiones y rebajes en forma de $\mathrm{V}$ que se interponen entre los mangos y las cazoletillas reflejan la separación entre la zona ya desprovista de piel y otra todavía con ella, como correspondería a los cuartos de un animal ya desollado (fig. 2).

Los tres pithoi son, sin duda, las piezas más llamativas en este conjunto. Su forma es bien conocida en el repertorio de la producción a torno de época Orientalizante, pero su decoración los convierte en ejemplares poco corrientes. Todos los motivos, tanto geométricos como figurativos, están pintados en tonos rojos y negros, a veces conjugados con el propio de la superficie de la vasija, dando impresión de policromía.

En el mayor de los tres $(75 \mathrm{cms}$. de h.), un cortejo de cuatro grifos, ataviados con un faldellín que cuelga del antepecho, desfila ceremoniosamente entre abundante vegetación de lotos. Son seres híbridos, con cabeza, cuello y alas de ave, cuerpo de ungulado corredor y rabo de bóvido o león (figs. 3 y 4).

En las cerámicas orientalizantes del poblado de Montemolín, próximo a Carmona, encontramos paralelos para la composición del friso y la forma de tratar detalles como el faldellín o el ala partida longitudinalmente en dos (Chaves y De la Bandera 1986: figs. 1,5 y 20), pero no hemos tenido ninguna fortuna en la búsqueda de modelos iconográficos para la figura completa de estos grifos, tan diferentes de la que parece la imagen canónica (Bisi 1965; Delplace 1980; Vidal de Brandt 1973). La cabeza ornitomorfa de los grifos de Carmona recuerda, sobre todo, la de las aves representadas varios siglos después en la cerámica ibérica del círculo Elche-Archena, que se fecha desde fines del siglo III al I a.C. (Pericot 1979: láms. 47, 57, 58 y 119). Se da la circunstancia de que estas últimas se creían inspiradas en modelos fenicios antiguos, que, sin embargo, hasta ahora eran desconocidos (Elvira 1979: 206).

Los otros dos vasos ( 59 y $56,6 \mathrm{cms}$. de h.) están pintados con un motivo de flores y capullos de loto entrelazados (figs. 5 y 6). Ambos temas son semejantes entre sí salvo en pequeños detalles, pero de ejecución muy diferente. El motivo goza de una larga tradición en Oriente, donde encontramos numerosos paralelos desde el II milenio en las más diversas manufacturas artesanales, sobre todo en metal (Markoe 1985: 232, 242, 243 y 272) y en marfil (Decamps de Mertzenfeld 1954: láms. XIV: 147 (1) y (2), XCVI: 920-922 y CVI: 969, entre otros). En cuanto a la cerámica, existen grandes semejanzas entre la decoración de las piezas de Carmona y la de unas grandes ánforas chipriotas con la misma cronología, pues están fechadas entre el 700 y el 600 a.C. (Karageorghis y Des Gagniers 1974: láms VIII.10 y 11).

Por su parte, las manufacturas orientalizantes de la Península Ibérica ofrecen también abundantes ejemplos de la misma decoración, tanto en metal (Carriazo 1973: figs. 20 y 21; Blázquez 1968: fig. 18, lám. 17A) como en marfil (Aubet 1980: 42-43, fig. 14, láms. X-XII) o en los huevos de avestruz de Villaricos (VII-VI a.C) (Astruc 1951: láms. LV,9; LVI,271, 458, 817, etc.) y de Ibiza (VI-III a.C.) (San Nicolás 1985: 98 y tabla IV, lám. IV). De su representación sobre cerámica son buenos ejemplos los vasos fragmentados de Setefilla (Aubet 1982a: fig. 4 y lám. IB) y de Montemolín (Chaves y De la Bandera 1992: fig. 9). A juzgar por los datos conocidos, parece que, al menos en el Alto Guadalquivir, el motivo sufre un proceso de acusada esquematización entre los siglos VII/VI y IV a.C. (Belén y otros 1997: 163 y fig. 37: 6, 8-10). 
2.2. La interpretación funcional del complejo arquitectónico de Saltillo y la del singular conjunto que rápidamente hemos presentado no es fácil, pero algunos datos nos llevan a considerar que los objetos que examinamos podrían constituir un equipo asociado a prácticas cultuales que se realizaban en un complejo sagrado de naturaleza urbana. Nuestra hipótesis está fundamentada, sobre todo, en el análisis de los materiales, pero ha tenido también en cuenta las características del ámbito en que se hallaron y las de los edificios que se le superponen, así como las del registro que a estos otros se asocia.

a).- La simple contemplación de las piezas de Saltillo induce a pensar que no constituyen un ajuar doméstico corriente. Parece claro que son en su mayor parte objetos de lujo, manufacturas valiosas realizadas por artesanos especializados que utilizaban materias primas caras y exóticas, como en el caso de las cucharas de marfil. En cuanto a los grandes vasos pintados, cabría argumentar que se trata de un equipo costoso adquirido por las élites del lugar (Murillo 1989: 160), pero nosotros pensamos que los motivos representados sobre estas cerámicas tienen un valor simbólico y no meramente decorativo (cf. Pachón y otros 1989-90: 252-253; Tortosa 1996: 157 y 386, nota 40). Detalles como las diferencias entre animales con y sin "barbas" en la pieza de los grifos, o la forma de rematar con una flor de pétalos caídos, como si estuviera marchita, la cadena de lotos abiertos y cerrados que decora las otras dos vasijas del conjunto, encierran, en nuestra opinión, un lenguaje en clave simbólica cuyos códigos no sabemos descifrar porque no estamos iniciados en ese lenguaje (Olmos 1992: 41).

Por otra parte, la flor de loto aparece con frecuencia como atributo de divinidades femeninas en el mundo semita. Por citar algunos ejemplos, flores de loto abiertas y cerradas, entrelazadas, adornan el vestido de la Astarté que figura en la placa de bocado de caballo conocida como "bronce Carriazo" (Carriazo 1973: figs. 20 y 21). Una flor de loto tiene asimismo en las manos la diosa representada en uno de los relieves de Pozo Moro (Blázquez 1995: 111; cf. Bonnet 1996: lám.VI,1); una flor de loto sostiene entre las alas Astarté-Tanit en las terracotas ibicencas (Aubet 1982b: 14). Astarté y Tanit son diosas astrales, dispensadoras de la vida y protectoras en la muerte, y un ciclo vital, de nacimiento, plenitud y muerte, se nos antoja que podría estar representado en los píthoi de las cenefas florales. Seguramente no es ninguna casualidad que los paralelos que hemos mencionado más arriba de vasos, metálicos o cerámicos, decorados con este mismo motivo procedan de contextos religiosos de carácter funerario.

Idéntica significación religiosa posee la roseta (Kukahn 1962: 80), símbolo, una vez más, de Astarté y de Tanit (Aubet 1982b: 37; Blázquez 1997: 80 y 85; Rindelaub y Schmidt 1996: 50). En la cerámica de Elche, la roseta unas veces acompaña y otras sustituye a la imagen de la divinidad, una diosa alada, que adopta indistintamente forma vegetal, animal o humana (Olmos 1992: 41).

Del contenido de los vasos, un aspecto que podría contribuir a aclarar un poco la cuestión, no sabemos nada seguro. En las vasijas decoradas con flores de loto se aprecian pérdidas del color de la decoración en sentido vertical, desde la boca a la mitad del cuerpo, como si se hubiera derramado un líquido, tal vez vino, que al resbalar sobre la pared hubiera ido degradando el color de la pintura. De hecho, el informe de restauración señala la presencia de restos de pigmentos rojos solubles en agua en el fondo de estos vasos, pero no precisa si se trata de restos orgánicos o inorgánicos. En cualquier caso, y puesto que los tres píthoi están lañados, si contuvieron vino debió ser antes de que se rompieran y fueran reparados para destinarlos a almacenar sólidos, tal vez también relacionados con prácticas cultuales. Algunas pistas en este sentido nos da el vaso de los grifós que contenía nódulos compactos de color rojo granate ${ }^{6}$. En textos del Antiguo Testamento se recogen usos litúrgicos de materias colorantes como sucedáneo de la sangre, en rituales de purificación por ejemplo (Caquot 1979: 169), y aunque hubieran servido como colorante para pintar paredes y suelos -que es una posibilidad que tampoco excluimos-, este mismo hecho no está desprovisto de connotaciones religiosas, como comentaremos más abajo.

6. Hematites con calcita y cuarzo como impurezas: Navarro Gascón, en Belén y otros, 1997: 297.

ISSN: 1133-4525 ISSN-e: 2255-3924

SPAL 6 (1997)

http://dx.doi.org/10.12795/spal.1997.i6.07 
En cuanto a las cucharas, el único paralelo que hemos encontrado para las mismas -también en marfilse halló en una tumba de la necrópolis que Delattre (1906: 30 y fig. 63) llamó "des Rabs" por considerar que era el lugar de enterramiento de los sacerdotes de Cartago, atribuyéndole, en consonancia con la dedicación de los allí sepultados, función de cucharilla para incienso. Este sector del cementerio de Sainte Monique se ha datado entre los siglos IV y II a.C. (Cintas 1976: 361; Tlatli 1978: 223-224). Similar uso se ha asignado a un ejemplar con el mismo diseño, pero de bronce y fechado en el siglo I d.C., que se conserva en el Museo Provincial de Cádiz ${ }^{7}$.

b).- Otro argumento a favor de la hipótesis que defendemos son las semejanzas que encontramos entre este ambiente más antiguo de Saltillo y otros complejos religiosos prerromanos, aunque ciertamente los ejemplos que nos sirven de contrastación son escasos.

Con carácter general podríamos mencionar el uso sistemático en la arquitectura religiosa del color rojo en paredes y suelos. Pavimientos rojos tienen las dependencias que en Cancho Roano (Celestino 1994: 294-296) y en Coria del Río ${ }^{8}$, albergan altares en forma de piel de toro. El edificio D de Montemolín, en cuyo interior se hallaron también vasos decorados con motivos orientalizantes, entre otros los restos de un píthos decorado con una procesión de grifos, tenía también los pisos pintados de rojo. Recientemente se ha defendido la hipótesis de que en este Edificio D se realizaran durante el siglo VI a.C. actividades relacionadas con el sacrificio de animales, de acuerdo con rituales de origen oriental (Chaves y De la Bandera 1995: 320).

El templo B de la Illeta dels Banyets, en Campello (Alicante), que Llobregat (1993: 426) fecha entre fines del V y fines del IV a.C. y considera de tradición semita, tenía la fachada pintada de rojo. Durante su excavación se encontró, como en Carmona, un montón de terrones arcillosos de color "rojo cinabrio" (Llobregat 1983: 491).

c).- La hipótesis acerca de la funcionalidad religiosa del edificio inferior de Saltillo queda reforzada al analizar los restos que se le superponen. El complejo constructivo más reciente, cuyo final situamos a mediados del siglo $\mathrm{V}$ a.C., no presenta rasgos arquitectónicos que excluyan otros usos, pero tampoco vemos en él nada que se oponga a esta consideración. En ámbitos sagrados es frecuente encontrar parecida combinación de espacios abiertos y cerrados, bancos adosados a las paredes sobre los que se depositan las ofrendas y hogares (Fantar 1986: 170-173 y 188-189). Tal vez, más que hogar, fuera más apropiado llamar altar a la plataforma de adobes del horizonte constructivo más reciente de Saltillo (cf. De Vaux 1992: 521).

En cuanto a los materiales que se asocian a este contexto, más atrás hemos señalado que la mayor parte de la cerámica que se recuperó en los niveles de abandono del edificio, fechado a mediados del siglo V a.C., corresponde a envases -ánforas o vasos cerrados de boca estrecha- $y$, sobre todo, a vasos abiertos, vasos para beber, muchos de ellos caliciformes como los que portan los oferentes de los santuarios ibéricos, que después de haberlos usado posiblemente en actos de libación, se rompían o se dejaban inservibles.

Por otra parte, en relación con testimonios de una posible continuidad en el uso cultual de este lugar durante la etapa romana, si bien los restos documentados en la excavación pueden considerarse poco significativos ${ }^{9}$, no está de más recordar la noticia de que, al hacer desmontes para las obras de la casa del Marqués del Saltillo en el siglo XVII, aparecieron aras y lápidas con inscripciones latinas, votivas y funerarias, que mencionan a personas vinculadas al culto de divinidades del panteón romano (Fernández López 1986:

7. $\mathrm{N}^{\circ}$ de inv ${ }^{\circ} 1985-6427-8888$.

8. Excavaciones realizadas recientemente en el Cerro de San Juan por un equipo dirigido por J.L. Escacena.

9. De las estructuras constructivas posteriores a los tres complejos que comentamos, sólo se ha podido datar con seguridad en época romana una cisterna que se excavó, precisamente, en el mismo lugar por el que se accedía a la habitación en que se hallaron los pithoi. 
11-12, 42 y 311-313). Estos documentos se han considerado falsos ${ }^{10}$, pero podría ser algo más que una curiosa coincidencia el que vinieran a hallarse en un lugar que parece que fue sagrado desde antiguo y que mantiene este mismo carácter aún hoy. Sobre el solar colindante con la casa-palacio del Marqués de Saltillo, se emplaza la iglesia de San Blas, que se construyó en la segunda mitad del siglo XIV sobre los restos de un conjunto religioso anterior, mezquita o sinagoga según diferentes tradiciones (cf. Hernández Díaz y otros 1943: 176; Lacave 1992: 355). En otras ocasiones la arqueología ha confirmado que la naturaleza sacra de un lugar se ha perpetuado a través de los tiempos (cf. Llobregat 1994: 174; Hachuel y Marí 1988: 58).

\section{ASTARTÉ Y EL CARAMBOLO}

\subsection{Un entorno costero (mapa 1)}

Para entender El Carambolo en el contexto de la colonización fenicia del bajo Guadalquivir es necesario hacer una recomposición detallada del paisaje antiguo de la comarca, porque, si bien el yacimiento se encuentra hoy a casi setenta kilómetros en línea recta del litoral atlántico más cercano (las playas onubenses de Matalascañas), en los tiempos en que el asentamiento estuvo poblado, es decir, en la primera mitad del primer milenio a.C., se trataba en realidad de un punto costero. De forma poética, Avieno (Ora Mar. 265) recoge ya una descripción de este paleopaisaje, cuando dibuja una zona de humedales en la desembocadura del Guadalquivir próxima al "golfo tartésico". Se trata en realidad del mismo ambiente al que debe de referirse el pasaje de Trogo Pompeyo que conocemos a través de Justino (XLIV, 4-16) (García Moreno 1979), al afirmar que Gerión vivía en unas islas cercanas a la desembocadura del gran río de Tartessos. Dicho contexto paleogeográfico estaba formado por un amplio estuario que, desde las estribaciones más septentrionales del Aljarafe, y con una anchura de cinco o seis kilómetros, precedía al amplio golfo que ocupaba lo que hoy son las inmensas llanuras de la comarca de Las Marismas. A este vasto estero se asomaba toda la cornisa oriental del Aljarafe desde su orilla oeste, mientras que en la de levante emergían con relieve más suave las terrazas de la margen izquierda del Guadalquivir. La meseta aljarafeña caía prácticamente a plomo sobre las aguas del estuario, hasta el punto de que todavía hoy se han conservado en el paisaje comarcal auténticos acantilados fósiles, como los que pueden verse a la altura de San Juan de Aznalfarache, Coria y La Puebla del Río(Ojeda 1989). Hasta tiempos históricos relativamente cercanos, la cartografía ha recogido con mayor o menor lujo de detalles estas profundas ensenadas (Astillero 1995: 216), hoy en gran parte colmatadas por aluviones holocénicos muy recientes. Sobre el otero que forma la cornisa del Aljarafe se alzaba El Carambolo frente a Sevilla, en un punto en que tal vez la navegación quedaba gravemente obstaculizada si no se hacía trasbordo de las mercancías a naves más pequeñas para seguir remontando el río ${ }^{11}$, lo que ya fue advertido en época romana por Estrabón (III, 2, 3) (Chic 1978: 8-9). Las inundaciones de los últimos años nos han proporcionado una imagen cabal de lo que fue este primitivo paisaje.

Gracias a los estudios de Gavala (1959) y a los posteriores de Menanteau (1982), así como a los más recientes sondeos geológicos del Instituto Arqueológico Alemán, conocemos con relativa precisión desde

10. Como tales se recogen en el CIL II sup. $n^{\circ}$ 502. Cándido María Trigueros publicó algunas de estas inscripciones en el vol. 1. de las Memorias literarias de la Academia Sevillana de Buenas Letras, en 1773, indicando que las lápidas se habían empleado después en la construcción de las gradas del altar mayor del convento de Agustinas Descalzas de Carmona. La reputación de Trigueros como "inventor de cosas que jamás han sido" (Fernández López 1886: 14, nota 1), restó crédito a la información que, sin embargo, algunos autores dan por verídica (Fernández López 1886: 322; Aguilar Piñal 1987: 43-45), o, al menos, no descartan que lo sea (Mora 1988: 346 y 348).

11. Esta necesidad ha sido al menos el argumento de más peso para explicar el origen del puerto sevillano, situado a la misma latitud que El Carambolo (Collantes de Terán 1977: 41; Blanco 1979: 88). 
Coria del Río, punto donde el estuario se estrechaba (Arteaga y otros 1995: 116), hacia el sur la antigua línea de costa; en dirección norte sabemos al menos que la comarca constituyó una zona de humedales parecidos a los que hoy conforman Doñana (Menanteau y Clemente 1977). En este ambiente palustre nacieron al unísono Sevilla y El Carambolo (Pellicer 1997). Y como hasta época romana al menos el vado más meridional se encontraba aguas arriba (Corzo 1991: 98), las comunicaciones directas entre la Sevilla protohistórica y El Carambolo debieron llevarse a cabo necesariamente por vía acuática.

A la vista de estos datos, las explicaciones que tengan que ver con las razones que originaron el nacimiento de ambos enclaves deberán tener presente dicho ambiente costero. Así pues, cuando nos planteemos hipótesis sobre el papel de la colonización fenicia en la zona deberemos dejar al margen de momento aquellas propuestas que hablan de una presencia semita con fines agrícolas en el interior del territorio tartésico (González Wagner y Alvar 1989), simplemente porque en este caso no estamos sino en pleno litoral atlántico. Por consiguiente, tanto Spal (Sevilla) como El Carambolo, además de otros asentamientos más o menos cercanos (Osset, Orippo, Caura, etc.), deben estudiarse para esta época como lugares costeros, y por tanto afectados por los mismos intereses que llevaron a la colonización fenicia de carácter comercial a tomar un papel relevante en el área gaditana.

\subsection{Algunos datos arqueológicos a examen}

Carriazo (1973) llamó Carambolo Alto y Bajo, respectivamente, a los lugares en que apareció el tesoro que ha dado celebridad al yacimiento y al poblado situado en la ladera. Sea por esta razón, o porque los resultados de las excavaciones fueron diferentes en una y otra, se suele olvidar que las dos zonas integran un mismo yacimiento, y que, en consecuencia, no deben considerarse de forma aislada.

Se ha prestado mucha atención a los hallazgos del Carambolo Alto al haberse considerado que suponen una buena muestra de la cultura autóctona del Bronce Final; también se ha atendido extensamente a la interpretación del contexto en que se hallaron (cf. Aubet 1992 y 1992-93). Carriazo receló de que lo que él mismo había llamado "fondo de cabaña" fuera realmente una modesta estructura de habitación. Las exclusivas cerámicas a mano con ricas decoraciones geométricas pintadas que contenía, anteriores a que sirviera de escondrijo al tesoro, desdecían de la pobreza del sistema constructivo de la supuesta vivienda (Carriazo 1973: 233-234). Años más tarde, Blanco (1979: 95-96) identificó el "fondo de cabaña" como un lugar de culto semejante a los que en el mundo egeo caracterizan las etapas Geométrica y Orientalizante, templos que "sólo por la singularidad de los ajuares se distinguían de las casas". Recientemente, Blázquez (1995: 115) ha sugerido que en esta choza-santuario del Carambolo debió recibir culto Astarté, la diosa representada sobre un trono en un exvoto de bronce hallado, al parecer, en el mismo cerro antes que el tesoro (Blanco 1979: nota 106 bis). La inscripción fenicia grabada en el escabel sobre el que la diosa apoya los pies se ha fechado entre mediados del siglo VIII y principios del VII a.C. (Bonnet 1996: 127-131). Las alhajas que componen el tesoro, aunque de datación posterior, se interpretan también como elementos de uso cultual (Blázquez 1995: 115; Caballos y Escacena 1992: 66).

La relación de este hipotético lugar sagrado con el poblado está por explicar. No es un problema que vayamos a resolver en esta comunicación, pero sí queremos presentar unos datos entresacados de la memoria de excavaciones del Carambolo Bajo que, en nuestra opinión, permiten sugerir una nueva valoración de la naturaleza del yacimiento. 
En verdad, no siempre nos ha resultado fácil seguir el discurso del profesor Carriazo e identificar sobre los planos "12 "laberínticos" de las excavaciones las estructuras que va describiendo (cf. Carriazo 1973: 235) (fig. 7). Por otra parte, el relato que nos ha dejado de sus trabajos, omite, en general, detalles que hoy nos parecen esenciales, como el contexto preciso en que se hallaron los diferentes conjuntos de materiales, con indicación, al menos, del nivel a que corresponden.

De las cuatro fases de construcción que distinguió, la más antigua, el nivel IV, es la que parece mejor delimitada, sea porque los escasos restos que la representan se diferenciaban bien de los que se le superponían (Carriazo 1973: 256), o porque al ser los que más se aproximaban a la arquitectura que se había imaginado para Tartessos, se documentaron con mayor atención ${ }^{13}$. A este nivel correspondía una dependencia que Carriazo (1973: 277-278) describe en los siguientes términos:

"Fue casi a la mitad del lado corto y más septentrional de la zona de excavación, al Norte de la primera habitación excavada y del muro suelto contiguo, donde descubrimos, el día 12 de enero de 1961, un andén o repisa de ocho sillares perfectamente labrados y escuadrados, de unos $20 \times 40 \mathrm{cms}$. y unos 8 de altura, semejantes a robustos ladrillos, puestos horizontales, adosados a un muro, como un banco seguido. Eran los primeros y siguen siendo los únicos testimonios de una arquitectura noble empleados en el poblado de un modo sistemático".

Precisa el autor que los sillarejos asentaban sobre un macizo de albañilería y que en la misma habitación, a medio metro de la repisa, localizó un pilar, "el más claro de todo el poblado", de "hasta doce o catorce pisos de adobes rosados", de unos $8 \mathrm{cms}$. de grosor (Carriazo 1973: 261 y 278).

Los materiales que encontró en este espacio, que no se excavó completo porque continuaba fuera del área acotada para la intervención arqueológica, constituyen el conjunto más rico de todo el poblado, según se desprende de los comentarios de Carriazo (1973: 278):

"Encima de los sillares no había nada que pudiera orientar sobre su destino; ni siquiera parecía más denso el depósito de fragmentos de cerámica, que en este departamento y nivel ha sido abundantísima, de las especies más selectas, como los soportes de vasos, acampanados, que han salido aquí de modo casi exclusivo".

Con relación a esta misma estancia, indica (Carriazo 1973: 294) que al limpiar las tierras desplomadas de los perfiles tras las lluvias del invierno 1961-1962, encontró "en el departamento de las losas, precisamente debajo del pilar reservado, con varios niveles de adobes rojos, que acabó por derrumbarse", dos fragmentos de una pila o gamella labrada en piedra caliza, de $47 \times 27 \mathrm{~cm}$ y $9 \mathrm{~cm}$. de altura.

Aún hay otros hallazgos que llaman también nuestra atención en El Carambolo Bajo. Se menciona en la memoria de los trabajos, sin hacer referencia a su posición estratigráfica, una habitación "recortada por muretes de planta irregular" situada en el ángulo sur de la excavación (Carriazo 1973: 273):

"(...) En el borde delantero de esa habitación, cubierta casi por completo con un tosquísimo murete, apareció una piedra horizontal, cuya superficie visible parecía labrada casi como una media columna. La limpiamos y levantamos con sumo respeto, pensando que habíamos encontrado el primer elemento de arquitectura noble de todo el poblado. Pero entonces se vio que era una piedra natural, y que en todo caso no estaba labrada en verdadera semicolumna; por lo que la restituimos a su sitio. Encima tiene un gran bloque de sílex negro que casi parece obsidiana: Diríamos que el constructor o inquilino de este departamento sentía curiosidad por las piedras raras".

12. Los dos planos que facilita Carriazo (1973), el situado entre las págs. 272-273 y el que se reproduce en la fig. 206, difieren en muchos detalles.

13. Aunque coincidimos en general con Aubet (1992: 34), somos algo más optimistas a la hora de valorar la fiabilidad de parte de la documentación del Carambolo. 


\subsection{Una propuesta atrevida}

A Carriazo (1973: 278), el banco enlosado con sillares del Nivel IV le recordó "el asiento corrido en la sala del trono de Cnosos". Buscaba una arquitectura residencial de majestad pareja a la del tesoro, y cuando los resultados defraudaron sus expectativas, se resignó a la evidencia de haber excavado solamente un poblado de "vida relativamente refinada" (Carriazo 1973: 287). Sin embargo, rechazó de forma explícita que los ajuares que halló en esta dependencia y en el resto del poblado pudieran pertenecer a un lugar de culto (Carriazo 1973: 287), a pesar de que prefería imaginar para la pila de piedra "un uso religioso, litúrgico", frente a otras opciones más profanas, y de que identificó como posibles betilos un conjunto de pequeñas piezas halladas en distintos sitios durante la excavación (Carriazo 1973: 292).

El análisis conjunto de los datos que hemos examinado y la presencia de ajuares que no son tan corrientes en ambientes domésticos como pensaba nuestro investigador (Carriazo 1973: 287), nos llevan a proponer que los restos exhumados en el Carambolo Bajo corresponden a sucesivos complejos religiosos superpuestos, con orientación igual o parecida, que aglutinan espacios cerrados y espacios abiertos más amplios, pavimentados con losas.

La repisa enlosada de pequeños sillares del horizonte más antiguo podría ser un banco para depositar ofrendas, representadas aquí por las "especies más selectas": jarros de barniz rojo, envases para perfumes, platos y soportes, auténticos portaofrendas hallados "de modo casi exclusivo" en este ámbito. El "pilar de adobes más claro de todo el poblado", tal vez un altar de en torno a un metro de altura, y el recipiente de piedra caliza que pudo usarse como pila para abluciones o libaciones (lám. II), son otros posibles elementos cultuales presentes en esta estancia. Bancos para ofrendas, altares y pilas, constituyen elementos indispensables en un santuario. "La trompeta de Argantonio", identificada recientemente como thymiaterion (Izquierdo y Escacena 1998), podría ser parte del mobiliario de culto del edificio sagrado que substituyó al más antiguo del nivel IV.

"Las piedras raras" que se encontraron en otra habitación que desgraciadamente no podemos situar en el tiempo, ni con precisión en el espacio, podrían ser betilos, es decir, representaciones anicónicas de la divinidad o divinidades que recibían culto en el lugar ${ }^{14}$. Son sobradamente conocidos los cultos betílicos en la religión semita y su larga tradición, así como el atractivo añadido que poseían las piedras negras con aspecto de aerolito, real o supuesto, a la hora de conferirles carácter sagrado (Ribichini 1985: 121). Esencialmente betílico era el culto de Astarté (Ribichini 1985: 123), sin que falten por eso representaciones antropomorfas de la diosa, como la que reproduce el exvoto hallado en este mismo yacimiento.

Las piedras en cuestión podrían ser elementos relacionados con el culto a esta divinidad en el santuario del Carambolo, donde además de realizar sacrificios y ofrecer alimentos y perfumes, materializados en los hallazgos cerámicos que hemos comentado más arriba, en costosos vasos de piedra y en asadores de bronce, los fieles habrían depositado como exvoto elementos personales -broches de cinturón y fíbulas-, terracotas con forma de ave (fig. 8) y pequeñas imágenes de la divinidad alusivas a la doble forma -antropomorfa y anicónica- con que era representada (cf. Trebolle 1997: 89, nota 2).

Después de examinar directamente ${ }^{15}$ las piezas que Carriazo (1973: 292-293, figs. 210 y 211 ) consideró posibles betilos, hemos comprobado que la mayor parte de ellas, aunque pesadas, son de barro cocido y no de arenisca. A excepción de una que es con claridad un pie de vaso trípode, como bien sospechó el investigador, las restantes, en efecto, no parecen objetos corrientes. Nos han llamado especialmente la

14. Tampoco descartamos que la pieza labrada en forma de media columna fuera sólo el pedestal que sostuviera el bloque de sílex negro.

15. Agradecemos al Dr. F. Fernández Gómez, director del Museo Arqueológico Provincial de Sevilla, así como a los técnicos $\mathrm{D}^{\mathrm{a}}$ Luz Pérez Iriarte y D. José Antonio Fernández, la diligencia y cortesía con que han facilitado la consulta por nuestra parte de los materiales del Carambolo. 
atención tres de ellas que, al parecer, salieron agrupadas, "en una zona de la estratigrafía alterada por las raíces de un olivo" (Carriazo 1973: 293). Tienen entre 7 y $8 \mathrm{cms}$. de altura y forma de pequeños cilindros con uno de los extremos sensiblemente ensanchado. Uno de los ejemplares está provisto de una base plana, que le permite mantenerse perfectamente en posición vertical (fig. 9 y lám. 3); otro está pintado de rojo (fig. 10:1), como algunos massebot hallados en santuarios orientales (cf. González Echegaray 1997: 34). En las superficies convexas de los extremos de estas piezas no hay señales de uso, lo que descarta su utilización como majas o machacadores.

De momento, no hemos encontrado objetos de tipología semejante en la bibliografía consultada ${ }^{16}$, pero la dualidad de exvotos antropomorfos y betílicos en un mismo santuario no es desconocida. Sin ir más lejos, en la cueva de Es Cuyeram, además de las terracotas femeninas se hallaron betilos de piedra de forma cónica, de unos $15 \mathrm{~cm}$. de altura (Aubet 1982b: 33-34).

\subsection{El Carambolo y Spal}

La valoración que proponemos para El Carambolo exige tratar de la relación de este yacimiento con la Sevilla antigua. Ambos asentamientos surgieron a finales de la Edad del Bronce en unos momentos en que ya se había iniciado la implantación fenicia en las costas meridionales hispanas (Campos 1986; Pellicer 1997: 240-245) ${ }^{17}$.

La hipótesis que aquí sostenemos es que son dos establecimientos complementarios y de fundación coetánea promovida por los fenicios. En la zona baja instalaron una factoría comercial, eligiendo para ello una suave elevación, una isla prácticamente, en el punto del río en el que era necesario el trasbordo de mercancías a embarcaciones de menor calado para remontar el Guadalquivir. Esta propuesta no es novedosa en su totalidad, pues otros autores han defendido antes el origen fenicio de Sevilla e, incluso, su carácter de ciudad costera (Collantes de Terán 1977: 44; Blanco 1979: 86). Y aunque pudiera discutirse una posible filiación autóctona, como admiten algunos investigadores por el hallazgo en sus estratos más profundos de cerámica a mano indígena ${ }^{18}$ (Campos y otros 1988: 22), tanto la tradición mítica, que tiene a Hércules por fundador, como el topónimo Spal que la identifica, de clara raigambre semita (Díaz Tejera 1982: 20; Lipinski 1984: 100), recuerdan el papel principal que los colonos orientales tuvieron en el origen de la ciudad.

Nuestra hipótesis sostiene que, enfrente de Sevilla, a $3 \mathrm{~km}$ de la población en dirección oeste, los fenicios consagrarían un elevado promontorio a Astarté. El Carambolo es una de las colinas más altas de la cornisa oriental del Aljarafe. Había conocido una primera ocupación calcolítica, luego interrumpida (Carriazo 1973: fig. 418, izd ${ }^{\text {a }}$; Ruiz Mata 1978-79: 45-46), pero que tal vez había conseguido elevar algo más el cabezo natural con los depósitos antrópicos. Desde la zona que ocupó la Sevilla protohistórica, la línea del horizonte siempre oculta en los alrededores del Carambolo al Sol, a la Luna y a Venus. No resulta extraño, pues, que fuera ése el lugar elegido para erigir un santuario que respaldara la empresa fenicia en este entorno, y que además, dada su posición, sirviera de guía a los barcos que remontaban el estuario.

16. En Aharoni y otros (1975: lám. 12, $\mathrm{n}^{\circ} 6$ ), se reproduce un objeto de barro cocido, de forma y dimensiones parecidas, aunque está incompleto, hallado en el santuario de Lachish, que se describe como un "fragment of pillar shaped Ashtoreth figurine".

17. Recientemente, la calibración de las fechas radiocarbónicas de los contextos andaluces de la Edad del Bronce (Ruiz-Gálvez 1995; Castro y otros 1996: 208-209), ha remontado en un siglo muchas de las cifras que afectan al Bronce Final tartésico, pero paralelamente ha elevado en la misma proporción la datación tradicional de la colonización fenicia.

18. Esta asimilación automática entre la vajilla cerámica y la gente que la usó parte de una identificación errónea de los marcadores étnicos en el registro arqueológico, porque los utensilios descargados de ideología o de contenido simbólico no son el mejor baremo para diferenciar poblaciones distintas (Escacena 1992: 338). 
Como hemos expuesto más atrás, tampoco somos los primeros en señalar la existencia de un lugar de culto en El Carambolo, pero nuestra posición introduce matices diferentes. Defendemos que en esta colina del Aljarafe no existió un gran poblado, sino un importante santuario con las dependencias que son propias de estos enclaves sacros, incluidas, tal vez, las destinadas a la práctica de la prostitución sagrada (Lipinski 1995: 489). Los resultados negativos de las propecciones geofísicas realizadas recientemente en las laderas del cerro, podrían estar refrendando esta interpretación, ya que no se han detectado estructuras fuera de la zona excavada por Carriazo ${ }^{19}$. En cuanto al supuesto fondo de cabaña del Carambolo Alto, podría ser un pozo o una fosa ritual que contenía restos de las ofrendas que se depositaron en el santuario; así se explicarían los sucesivos niveles de incendio, la cantidad y calidad de las cerámicas que en él se hallaron, los fragmentos de cáscara de huevo de avestruz y la ocultación final del propio tesoro.

La fecha del 750 a.C. que se baraja para las primeras importaciones fenicias que llegan al denominado poblado bajo (Aubet 1992-93: 340), indica de forma aproximada el inicio de la ocupación del lugar. Aunque normalmente se ha supuesto una mayor antigüedad para "el fondo de cabaña" (Aubet 1992-93: 339-340), una revisión reciente de algunos materiales recuperados por Carriazo aboga por fechas no anteriores a mediados del siglo VIII a.C. también para este otro sector del yacimiento (Amores 1995: 167), en cuyos niveles de base, por otra parte, el excavador aseguraba haber encontrado cerámicas a torno (Carriazo 1973: 234, 482 y 493; cf. Aubet 1992-93: 339). La etapa fechada a lo largo de los siglos VII y VI a.C. es la mejor representada; destacan por su abundancia y variedad las cerámicas, pero también se han documentado fíbulas de tipo Alcores (Ruiz Delgado 1989: 135, mapa V), broches de cinturón de garfios (Cerdeño 1981: 39-40), asadores y braserillos de bronce. Por último, el hecho más significativo en relación con el momento final de la ocupación protohistórica del sitio es la ocultación del tesoro en el interior del supuesto fondo de cabaña ya en desuso. De acuerdo con los materiales arqueológicos exhumados, se suele situar este episodio entre fines del siglo VI y principios del V a.C., coincidiendo con la época de cambios que certifican el final del apogeo tartésico, la decadencia de los influjos fenicios arcaicos sobre el Bajo Guadalquivir y el paralelo renacimiento de viejas pautas culturales contrarias a las corrientes coloniales (Escacena 1989). Al contrario que otros muchos asentamientos del entorno, El Carambolo no continuó con vida después de su etapa tartésica. Este final precoz explica que los autores grecolatinos no pudieran transmitirnos su nombre, como sí lo hicieron con los topónimos Ilipa (Alcalá del Río), Osset (San Juan de Aznalfarache), Hispalis (Sevilla), Orippo (Torre de los Herberos, en Dos Hermanas) y Caura (Coria del Río), poblaciones inmediatas al propio Carambolo.

\section{BIBLIOGRAFÍA}

AGUILAR PIÑAL, F. (1987): Un escritor ilustrado: Cándido María Trigueros. Madrid, CSIC, Instituto de Filología.

AHARONI, Y. y otros (1975): Investigations at Lachish. The Sanctuary and the Residency.(Lachish V). (Publications of the Institute of Archaeology, 4). Tel Aviv, Gateway Pub. Inc.

ALVAR, J. (1990): "El contacto intercultural en los procesos de cambio", Gerión 8: 11-27.

(1991): "La religión como índice de aculturación: el caso de Tartessos", Atti del Il Congresso

Internazionale di Studi Fenici e Punici, vol. I: 351-356. Roma, CNR.

19. Trabajos realizados por la empresa Terra Nova LTd. a instancias de la Delegación Provincial de Cultura de Sevilla, con el fin de delimitar el yacimiento. El informe técnico no excluye que puedan existir estructuras no detectadas por las técnicas geofísicas empleadas, pero esto no parece probable según nos refiere D. José M. Rodríguez Hidalgo, arqueólogo de la Delegación, con quien hemos intercambiado puntos de vista y al que agradecemos que nos haya facilitado la consulta de dicho informe. 
- (1993): "Problemas metodológicos sobre el préstamo religioso", en Alvar, J. y otros (eds.), Formas de difusión de las religiones antiguas. Segundo Encuentro-Coloquio de ARYS. Jarandilla de la Vera, Diciembre 1990: 1-33. Madrid.

AMORES, F. (1995): "La cerámica pintada estilo Carambolo: una revisión necesaria de su cronología", Tartessos 25 años después 1968-1993 (Jerez de la Frontera): 159-178. Jerez, Ayuntamiento de Jerez.

ARTEAGA, O. y ROOS, A.-M. (1995): "Geoarchäologische Forschungen im Umkreis der Marismas am Río Guadalquivir (Niederandalusien)", Madrider Mitteilungen 36: 199-218.

ARTEAGA, O. y otros (1995): “El problema del 'Lacus Ligustinus'. Investigaciones geoarqueológicas en torno a las Marismas del Bajo Guadalquivir", Tartessos 25 años después: 99-135. Jerez, Ayuntamiento de Jerez.

ASTILLERO, J.M. (ed.) (1995): "Álbum cartográfico desde el Renacimiento a la cartografía moderna", en Historia del Paso del Estrecho de Gibraltar: 211-224. Cádiz, Sociedad Española de Estudios para la Comunicación Fija a través del Estrecho de Gibraltar.

ASTRUC, M. (1951): La Necrópolis de Villaricos, (Informes y Memorias 25). Madrid. Comisaría General de Excavaciones Arqueológicas.

AUBET, M.E. (1980): Marfiles fenicios del Bajo Guadalquivir, II. Acebuchal y Alcantarilla, Studia Archaeologica, 62. Valladolid, Universidad de Valladolid.

_ (1982a): "Cerámicas polícromas con motivos figurados de Setefilla (Sevilla)", En Homenaje a Conchita Fernández-Chicarro: 213-225. Madrid. Ministerio de Cultura.

- (1982b): El Santuario de Es Cuieram (Trabajos del Museo Arqueológico de Ibiza 8). Ibiza, Ministerio de Cultura.

- (1992): "Maluquer y la renovación de la arqueología tartésica", en Excavaciones en "El Carambolo" (Sevilla) (Clásicos de la Arqueología de Huelva 5). Huelva, Diputación Provincial de Huelva.

- (1992-93): "Maluquer y El Carambolo", Tabona VIII, vol. II: 329-350.

BELÉN, M. y ESCACENA, J.L. (1995): "Interacción cultural fenicios-indígenas en el Bajo Guadalquivir", Arqueólogos, Historiadores y Filólogos. Homenaje a Fernando Gascó, tomo I, en Kolaios. Publicaciones Ocasionales 4: 67-101. Sevilla.

BELÉN, M. y otros (1997): Arqueología en Carmona (Sevilla). Excavaciones en la Casa-Palaciodel Marqués de Saltillo. Sevilla, Consejería de Cultura de la Junta de Andalucía.

BERMEJO, J. (1982): Mitología y mitos de la Hispania prerromana. Madrid, Akal.

BISI, A.M. (1965): Il grifone. Storia di un motivo iconografico sull'Antico Oriente Mediterraneo. (Studi Semitici, 15). Roma, Centro di Studi Semitici.

BLANCO, A. (1979): Historia de Sevilla. I (1) La ciudad antigua (De la Prehistoria a los Visigodos). Sevilla, Universidad de Sevilla.

BLÁZQUEZ, J.M.(1968): Tartessos y los orígenes de la colonización fenicia en Occidente. Salamanca, Universidad de Salamanca.

— (1995): "El legado fenicio en la formación de la religión ibera", en I Fenici: Ieri, Oggi, Domani. Ricerche, scoperte, progetti (Roma, 3-5 marzo 1994): 107-117. Roma, CNR.

- (1997): “Astarté, Señora de los caballos en la Hispania prerromana", Rivista Studi Fenici XXV,1: 79-95.

BONNET, C. (1996): Astarté. Dossier docummentaire et perspectives historiques. (Contributialla Storia della Religione Fenicio-Punica II). Roma, CNR.

BONSOR, G.(1899): Les colonies agricoles pré-romaines de la Vallée du Bétis (Revue Archélogique, XXXV). París.

CABALLOS, A. y ESCACENA, J.L. (1992): Tartesos y El Carambolo. Sevilla, Ayuntamiento de Sevilla. 
CAMPOS, J. (1986): Excavaciones Arqueológicas en la Ciudad de Sevilla. El Origen Prerromano y la Hispalis Romana. Sevilla, Monte de Piedad y Caja de Ahorros de Sevilla.

— y otros (1988): Protohistoria de la ciudad de Sevilla. El corte estratigráfico San Isidoro 85-6

(Monografías de Arqueología Andaluza 1). Sevilla, Consejería de Cultura de la Junta de Andalucía.

CAQUOT, A.(1979): "El judaísmo desde la cautividad de Babilonia hasta la revuelta de Bar Kojba", en Puech, H-Ch. (dir.): Las Religiones en el Mundo Mediterráneo y en el Oriente Próximo. I. Formación de las religiones universales y de la salvación. Historia de las Religiones siglo XXI, vol. 5: 136-222. Madrid, Siglo XXI.

CARO BAROJA, J. (1971): “La "realeza” y los reyes de la España antigua”, Cuadernos de la Fundación Pastor 17. Madrid

CARRIAZO, J. de M. (1970): El tesoro y las primeras excavaciones en «El Carambolo» (Camas, Sevilla) (Excavaciones Arqueológicas en España 68). Madrid, Ministerio de Cultura.

(1973): Tartesos y El Carambolo. Madrid, Ministerio de Educación y Ciencia. (1974): Protohistoria de Sevilla. Sevilla, Ayuntamiento de Sevilla.

CASTRO, P.V. y otros (1996): Cronología de la Prehistoria Reciente de la Península Ibérica y Baleares (c. 2800-900 cal ANE) (BAR Intern. Ser. 652). Oxford, Tempus Reparatum.

CELESTINO, S. (1994): "Los altares en forma de "lingote chipriota" de los santuarios de Cancho Roano", Revista de Estudios Ibéricos 1. La escultura ibérica: 291-30. Madrid, UAM.

CERDEÑO, M.L. (1981): "Los broches de cinturón tartésicos", Huelva Arqueológica V: 31-56.

CINTAS, P. (1976): Manuel d'Archéologie Punique, vol. II. París, Ed. A. et J. de Picard.

COLLANTES DE TERÁN, F. (1977): Contribución al estudio de la topografía sevillana en la Antigüedad y en la Edad Media. Sevilla, C.S.I.C. y Monte de Piedad y Caja de Ahorros de Sevilla.

CORZO, R. (1991): Las Termas, la Ciudad y el Río de Sevilla en la Antigüedad. Excavaciones en la Calle Abades. Sevilla, Academia de Bellas Artes Santa Isabel de Hungría-Real Maestranza de Caballería.

CHAVES, F. y DELA BANDERA, M.L. (1986): "Figürlich verzierte Keramik aus dem Guadalquivir-Gebiet. Die Funde von Montemolín (bei Marchena, Prov. Sevilla)", Madrider Mitteilungen 27: 117-150.

_ (1992): "Problemática de las cerámicas «orientalizantes» y su contexto", en Untermann, J. y Villar, F. (eds.), Lengua y Cultura en la Hispania Prerromana. Actas del V Coloquio sobre lenguas y culturas prerromanas de la Península Ibérica: 49-89. Salamanca, Universidad de Salamanca.

- (1995): "El yacimiento tartésico de Montemolín", en Tartessos, 25 años después.1968-1993. Jerez de la Frontera: $315-332$. Jerez, Ayuntamiento de Jerez.

CHIC, G. (1978): "Consideraciones sobre la navegabilidad del Guadalquivir en época romana", Gades 1: 7-20.

DE VAUX, R. (1992): Instituciones del Antiguo Testamento. (5 $5^{\mathrm{a}}$ ed.). Barcelona, Herder.

DECAMPS DE MERTZENFELD, C. (1954): Inventaire commenté des ivoires phéniciens et apparentés découverts dans le ProcheOrient . París, Ed. E. de Boccard.

DELATTRE, A.L. (1906): La Nécropole des Rabs. Prêtes et Prêtresses de Carthage. Troisième année des fouilles. París.

DELPLACE, Ch. (1980): Le griffon. De l'archaïsme a l'époque Impériale. Étude iconographique et Essai d'interprétation symbolique. Bruselles-Rome, Institut Historique Belge de Rome (Études de Philologie, d'Archólogie et d'Histoire Anciennes).

DÍAZ TEJERA, A. (1982): Sevilla en los textos clásicos grecolatinos. Sevilla, Ayuntamiento de Sevilla.

ELVIRA, M.A. (1979): “Aproximación al "estilo florido" de la cerámica de Liria”,Archivo Español de Arqueología, 52: 205-225.

ESCACENA, J.L. (1989): "Los Turdetanos o la recuperación de la identidad perdida", en Aubet, M.E. (coord.): Tartessos. Arqueología Protohistórica del Bajo Guadalquivir: 433-476. Sabadell, Ausa.

(1992): "Indicadores étnicos en la Andalucía prerromana", Spal 1: 321-343. 
FANTAR, M. (1986): Kerkouane Cité Punique du Cap Bon(Tunisie).T. III. Sanctuaires et cultes. Societé Economie. Tunis, Institut National d'Archéologie et d'Art.

FERNÁNDEZ LÓPEZ, M. (1886): Historia de la ciudad de Carmona. Carmona.

GARCÍA MORENO, L. (1979): "Justino: 44,4 y la historia interna de Tartessos", Archivo Español de Arqueología 52: 111-130.

GAVALA, J. (1959): La Geología de la Costa y Bahía de Cádiz y el poema "Ora Maritima”, de Avieno. Madrid, Instituto Geológico y Minero de España. Edición facsímil en Cádiz, Diputación Provincial, 1992.

GONZÁLEZ ECHEGARAY, J. (1997): "Situación política de Israel en el siglo VIII”, en Ausín, S. (dir.): De La Ruina a la Afirmación. El entorno del Reino de Israel en el siglo VIII a.C.: 19-38. Estella (Navarra), Ed. Verbo Divino.

GONZÁLEZ WAGNER, C. (1983): “Aproximación al proceso histórico de Tartessos”, Archivo Español de Arqueología 56: 3-35.

(1986): "Notas en torno a la aculturación en Tartessos", Gerión 4: 129-160.

y ALVAR, J. (1989): "Fenicios en Occidente: la colonización agrícola", Rivista di Studi Fenici XVII,1: 61-102.

GRUZINSKI, S. y ROUVERET, A. (1976): “"Ellos son como niños». Histoire et acculturation dans le Mexique colonial et l'Italie méridionale avant la romanisation", Mélanges de l'École Française de Rome. Antiquité 88, 1: 159-219.

HACHUEL, E. y MARÍ, V. (1988): El santuario de la Illa Plana (Ibiza). Una propuesta de análisis. (Trabajos del Museo Arqueológico de Ibiza 18). Eivissa, Consellería d'Educació i Cultura, Govern Balear.

HERNÁNDEZ DÍAZ, J. y otros (1943): Carmona. Catálogo Arqueológico y Artístico. Tirada aparte del Catálogo Arqueológico y Artístico de la provincia de Sevilla t. I. Sevilla.

IZQUIERDO, R. y ESCACENA, J.L. (1998): “Sobre El Carambolo: «La Trompeta de Argantonio»”, Archivo Español de Arqueología 71: 29-36.

KARAGEORGHIS, V. y DES GAGNIERS, J. (1974): La céramique chypriote de style figuré. Age du Fer (1050-500 av. J.C.). Roma, Ed. dell'Ateneo.

KUKAHN, E. (1962): "Los símbolos de la Gran Diosa en la pintura de los vasos ibéricos levantinos", Caesaraugusta, PSANA: 19-20: 79-85.

LACAVE, J.L. (1992): Juderías y sinagogas españolas. Madrid, Ed. Mapfre.

LIPINSKI, E. (1984): “Vestiges phéniciens d'Andalousie", Orientalia Lovaniensia Periodica 15: 81-132. (1995): Dieux et déesses de l'Univers phénicien et punique. (Studia Phoenicia XIV). Leuven, Uitgeveri Peeters.

LLOBREGAT, E. (1983): "El templo ibérico de la Illeta dels Banyets", en Blázquez, J.M.: Religiones Prerromanas. Primitivas religiones ibéricas, t. II: 489-494. Madrid, Ed. Cristiandad. (1993): "L'illeta dels Banyets (el Campello, camp d'Alacant) ¿fou un empórion ?", en Padró, J. y otros (coords.): Homenatge a Miquel Tarradell: 421-428. Barcelona, Curial Edic. Catalanes

(1994): “Tradición religiosa fenicio-púnica en Contestania", en González Blanco, A. y otros: Coloquios de Cartagena, I. El Mundo Púnico. Historia, Sociedad y Cultura (Cartagena, 17-19 de Noviembre de 1990): 169-175. Murcia, Ed. Regional de Murcia.

MARKOE, G. (1985): Phoenician Bronze and Silver Bowls from Cyprus and the Mediterranean. Classical Studies, 26. University of California Press, Berkley-Los Ángeles.

MENANTEAU, L. (1982): Les Marismas du Guadalquivir. Exemple de Transformation d'un Paysage Alluvial au Cours du Quaternaire Récent. París, Université de Paris-Sorbonne.

— y CLEMENTE, L. (1977): "Variaciones de la influencia marina y su incidencia en la transformación del paisaje aluvial del delta del Guadalquivir durante los dos últimos milenios", Actas de la Segunda Reunión Nacional del Grupo Español de Trabajo del Cuaternario: 167-176. Madrid, Grupo Español de Trabajo del Cuaternario. 
MORA, G. (1988): “Trigueros y Hübner. Algunas notas sobre el concepto de falsificación”, Archivo Español de Arqueología 61: 344-348.

MURILLO, J.F. (1989): "Cerámicas tartésicas con decoración orientalizante", Cuadernos de Prehistoria y Arqueología U.A.M. 16: 149-167.

OJEDA, J. (1989): "La dinámica litoral reciente de la costa occidental de Andalucía", El Cuaternario en Andalucía Occidental: 123-132. Sevilla, AEQUA.

OLMOS, R. (1992): “Religiosidad e ideología ibérica en el marco del Mediterráneo", en Vaquerizo, D. (coord.): Religiosidad y vida cotidiana en la España ibérica (Seminarios Fons Mellaria, 1991): 11-45. Córdoba, Excma. Diputación Provincial de Córdoba.

PACHÓN, J.A. y otros (1989-90): "Decoración figurada y cerámicas orientalizantes. Estado de la cuestión a la luz de los nuevos hallazgos", Cuadernos de Prehistoria y Arqueología de la Universidad de Granada 14-15: 209-272.

PELLICER, M. (1997): “El nacimiento de Sevilla”, Boletín de la Real Academia de Bellas Artes de Santa Isabel de Hungria XXV: 232-254.

— y otros (1977): "Para una metodología de localización de las colonias fenicias en las costas ibéricas: el Cerro del Prado", Habis 8: 217-251.

PERICOT, L. (1979): Cerámica ibérica. Barcelona, Ed. Polígrafa, S.A.

RIBICHINI, S. (1985): Poenus Advena. Gli dei fenici e l'interpretazione classica. Roma, CNR.

RINDELAUB, A. y SCHMIDT, K. (1996): "Les fouilles de l'Université de Hamburg au-dessous du Decumanus maximus à Carthage", CEDAC Carthage Bull. 15: 44-52.

RIVERA, M. (1975): "Modelos de aculturación en Arqueología", Primera Reunión de Antropólogos Españoles: 71-78. Sevilla, Universidad de Sevilla.

RUIZ DELGADO, M.M. (1989): Fíbulas protohistóricas en el surde la Península Ibérica. Sevilla, Servicio de Publicaciones de la Universidad de Sevilla.

RUIZ-GÁLVEZ, M. (1992): "Orientaciones teóricas sobre intercambio y comercio en Prehistoria”, Gala 1: $87-101$.

(1995): “Cronología de la Ría de Huelva en el marco del Bronce Final de Europa Occidental”, en Ruiz-Gálvez, M. (ed.): Ritos de Paso y Puntos de Paso. La Ría de Huelva en el Mundo del Bronce Final Europeo, en Complutum (Extra 5): 79-83. Madrid, Universidad Complutense.

RUIZ MATA, D. (1978-79): "Nuevos yacimientos campaniformes en la provincia de Sevilla”, Cuadernos de Prehistoria y Arqueología de la Universidad Autónoma de Madrid 5-6: 41-57.

SAN NICOLÁS, M.P. (1985): "Las cáscaras de huevo de avestruz fenicio-púnico en la Península Ibérica y Baleares", Cuadernos de Prehistoria y Arqueología U.A.M., 12: 75-100.

SCHULZ, H.D. (1995): "Holozäne Küstenlinie am Unterlauf des Río Guadalquivir zwischen Sevilla und der Mündung in den Atlantik", Madrider Mitteilungen 36: 219-232.

TEJERA, A. (1992-93): "El mito de Habis: poder y sociedad en Tartessos", Tabona VIII, II: 553-561.

TLATLI, S-E. (1978): La Carthage Punique. Étude urbaine. París, Librairie d'Amérique et d'Orient.

TORTOSA, T. (1996): "Imagen y símbolo en la cerámica ibérica del sureste”, en Olmos, R. (ed.): Al otro lado del espejo: Aproximación a la imagen ibérica (Colección Lynx. La arqueología de la mirada, vol. I): 145-162. Madrid.

TREBOLLE, J. (1997): "El monoteísmo y el aniconismo bíblico en relación con la iconografía israelita y con los cultos anicónicos del mundo semítico", en Ausín, S. (dir.): De la Ruina a la Afirmación. El entorno del Reino de Israel en el siglo VIII a.C.: 77-100. Estella, Ed. Verbo Divino.

VIDAL DE BRANDT, M.M. (1973): “La iconografía del grifo en la Península Ibérica”, Pyrenae, 9: 7-151. 

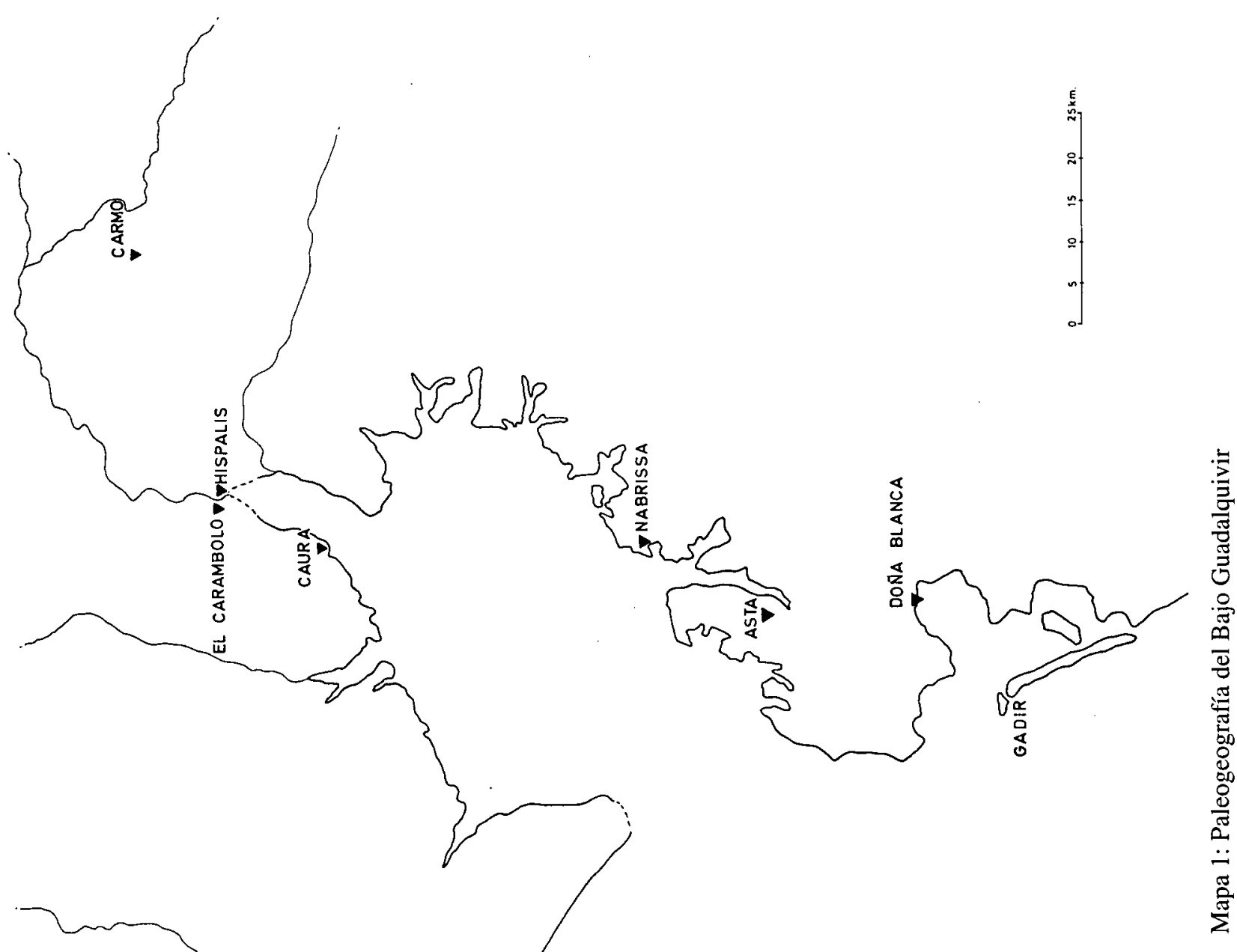

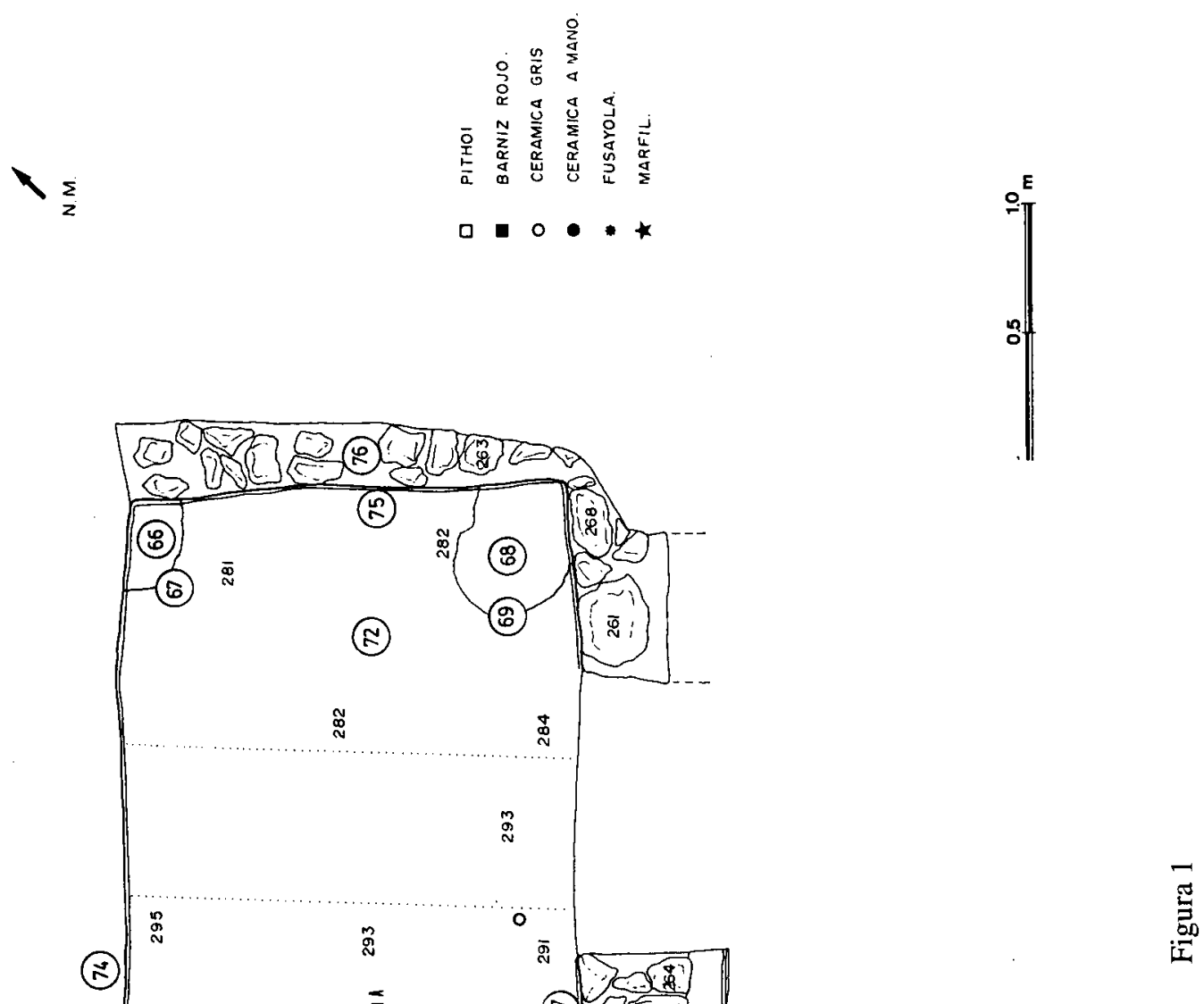

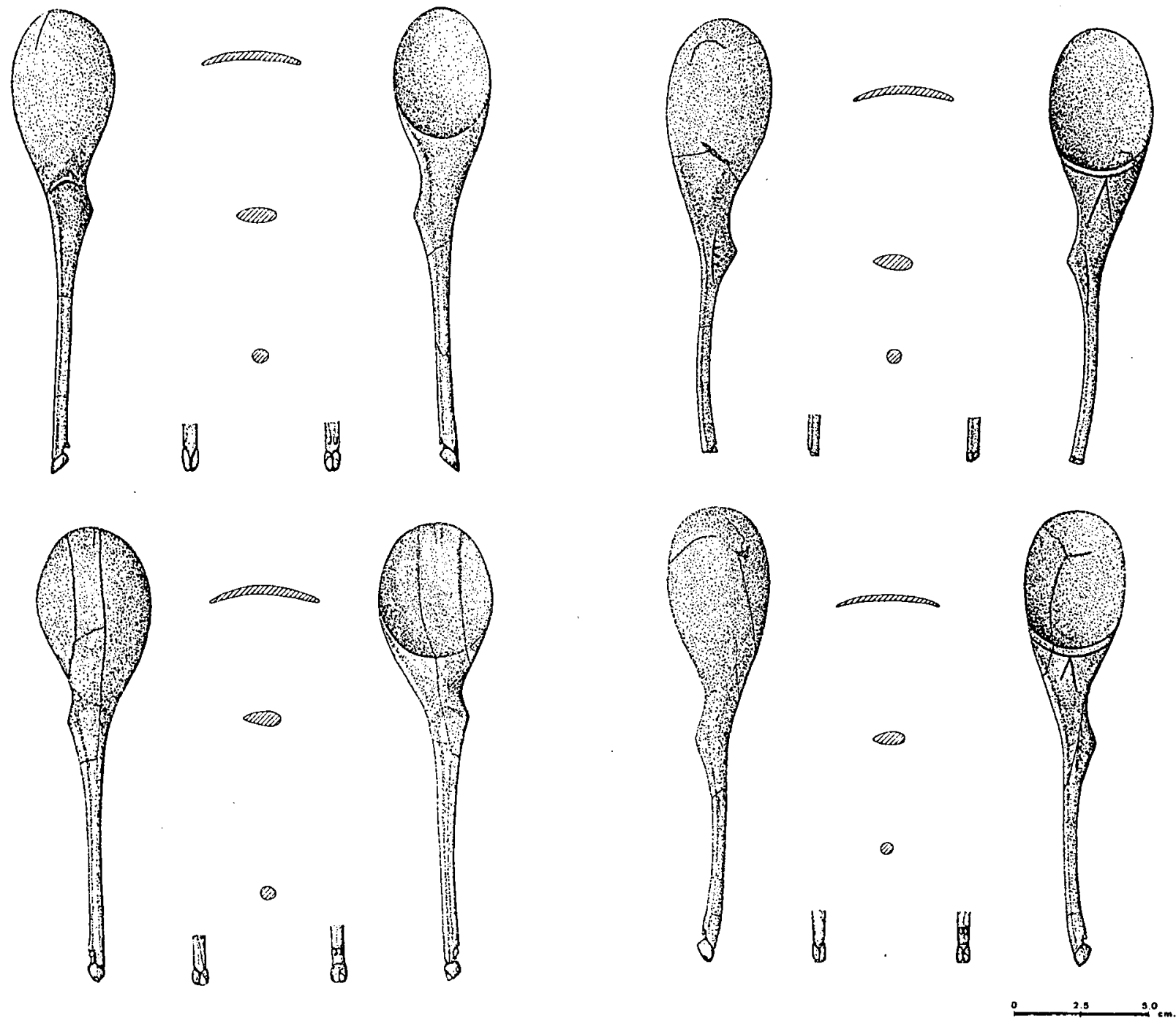

Figura 2 


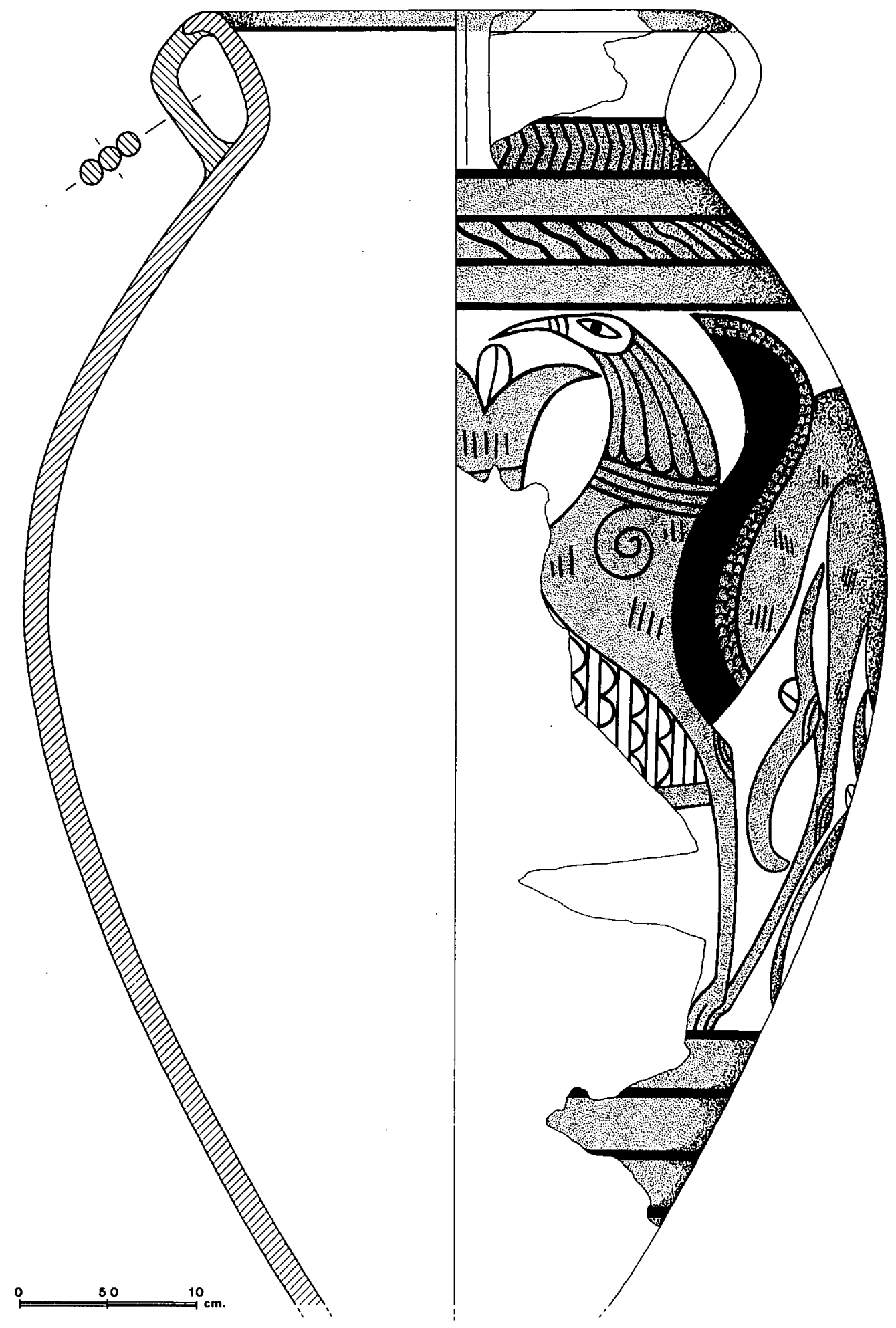

Figura 3 


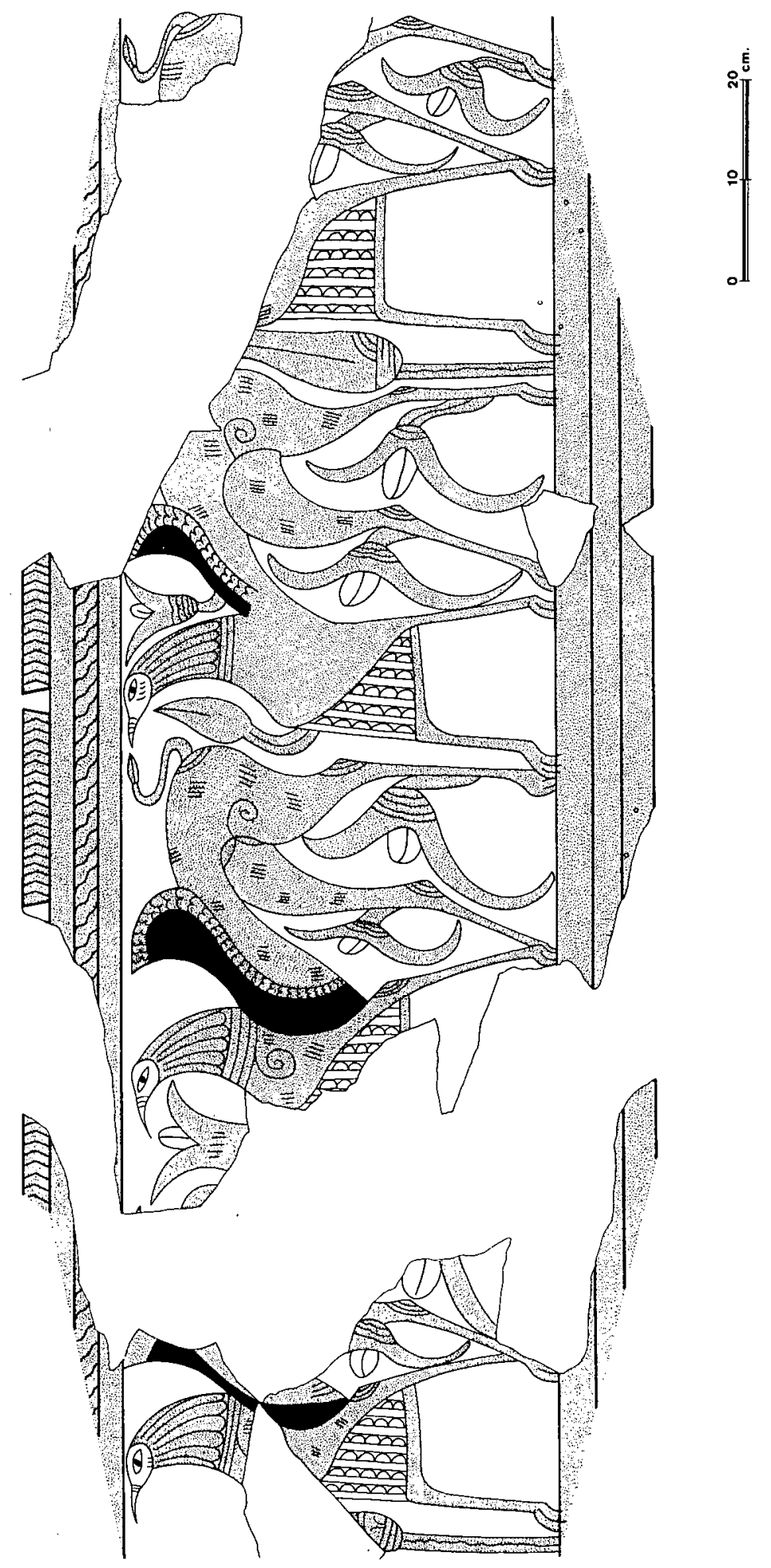

苞 

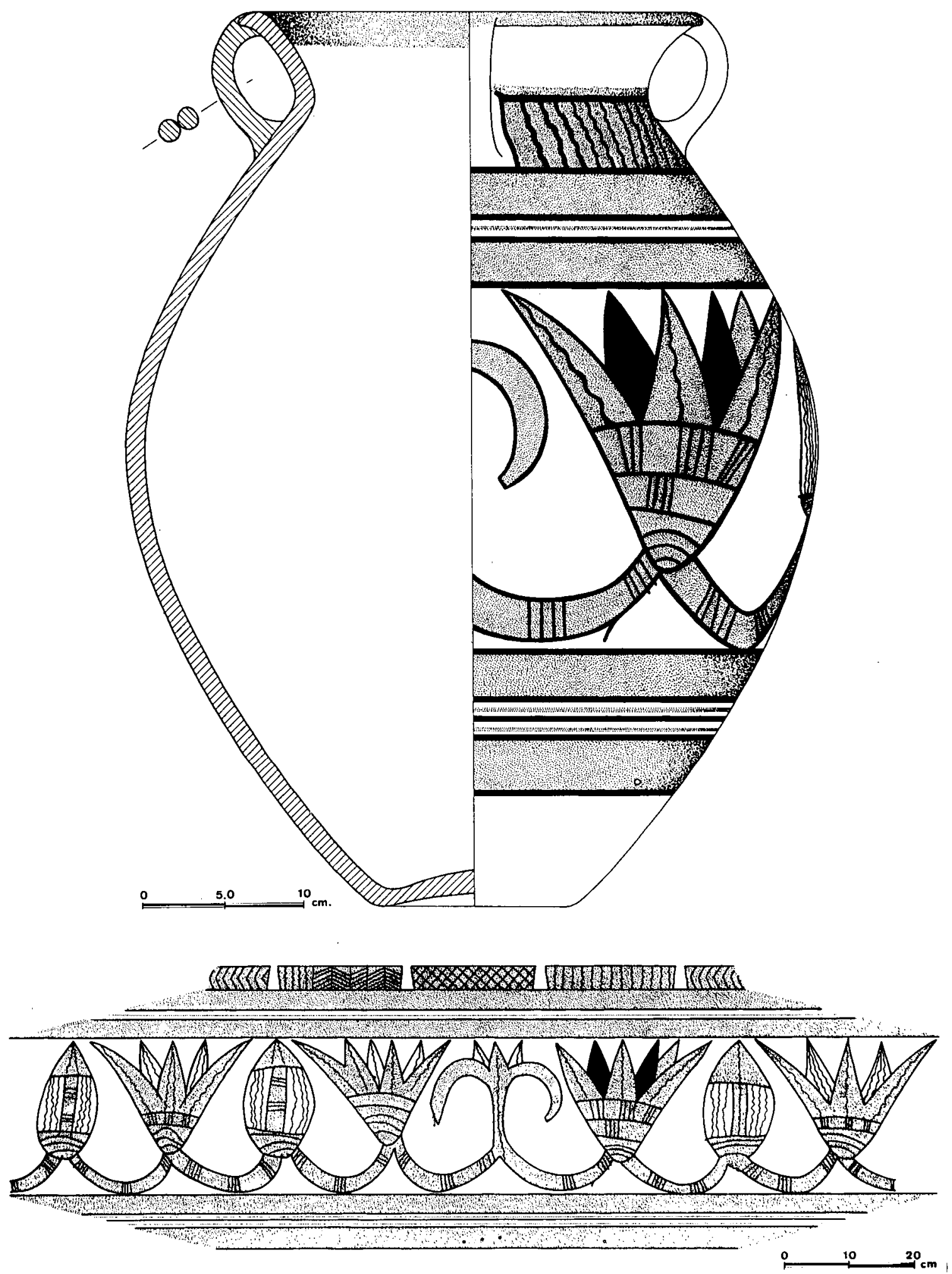

Figura 5 

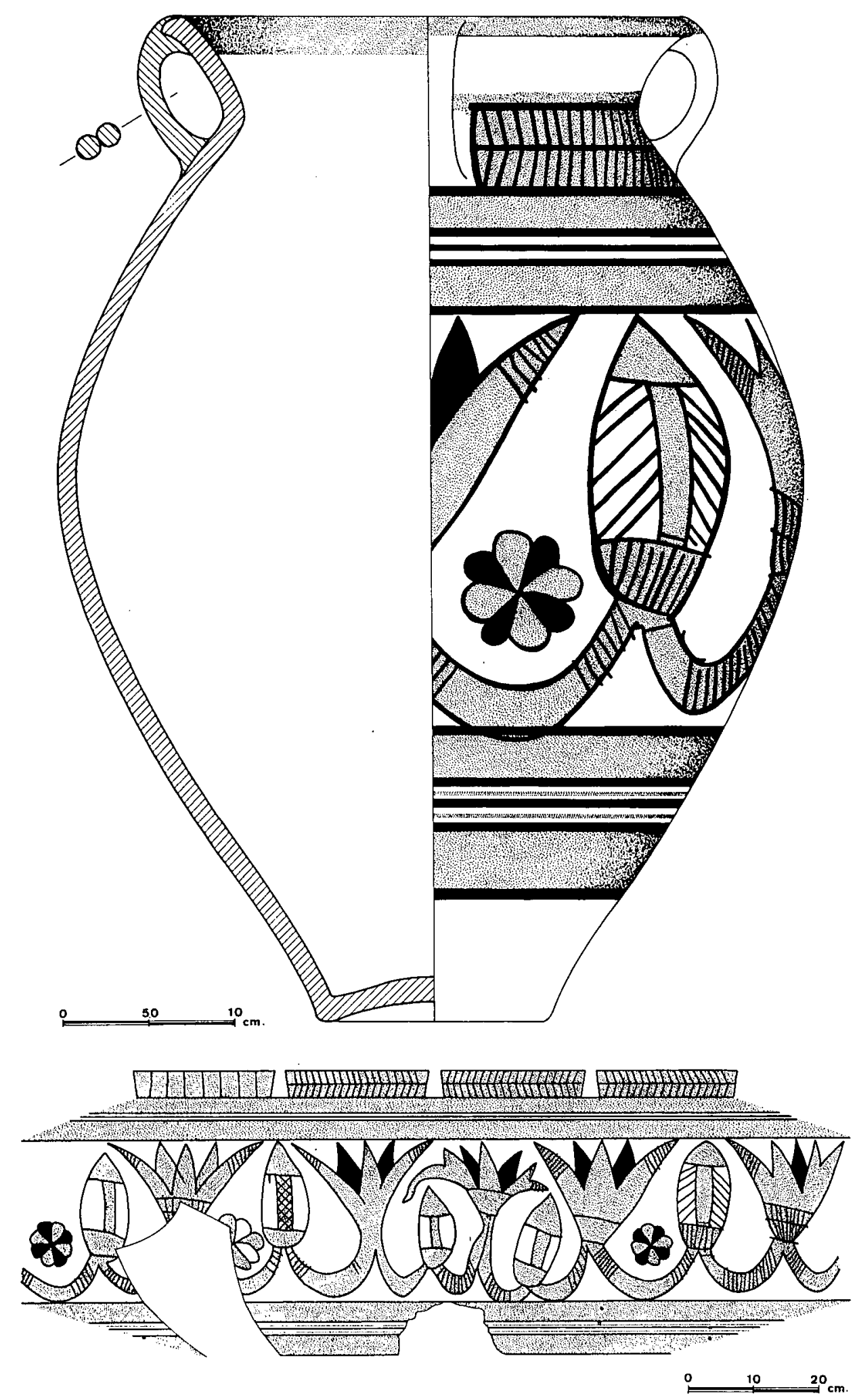

Figura 6 


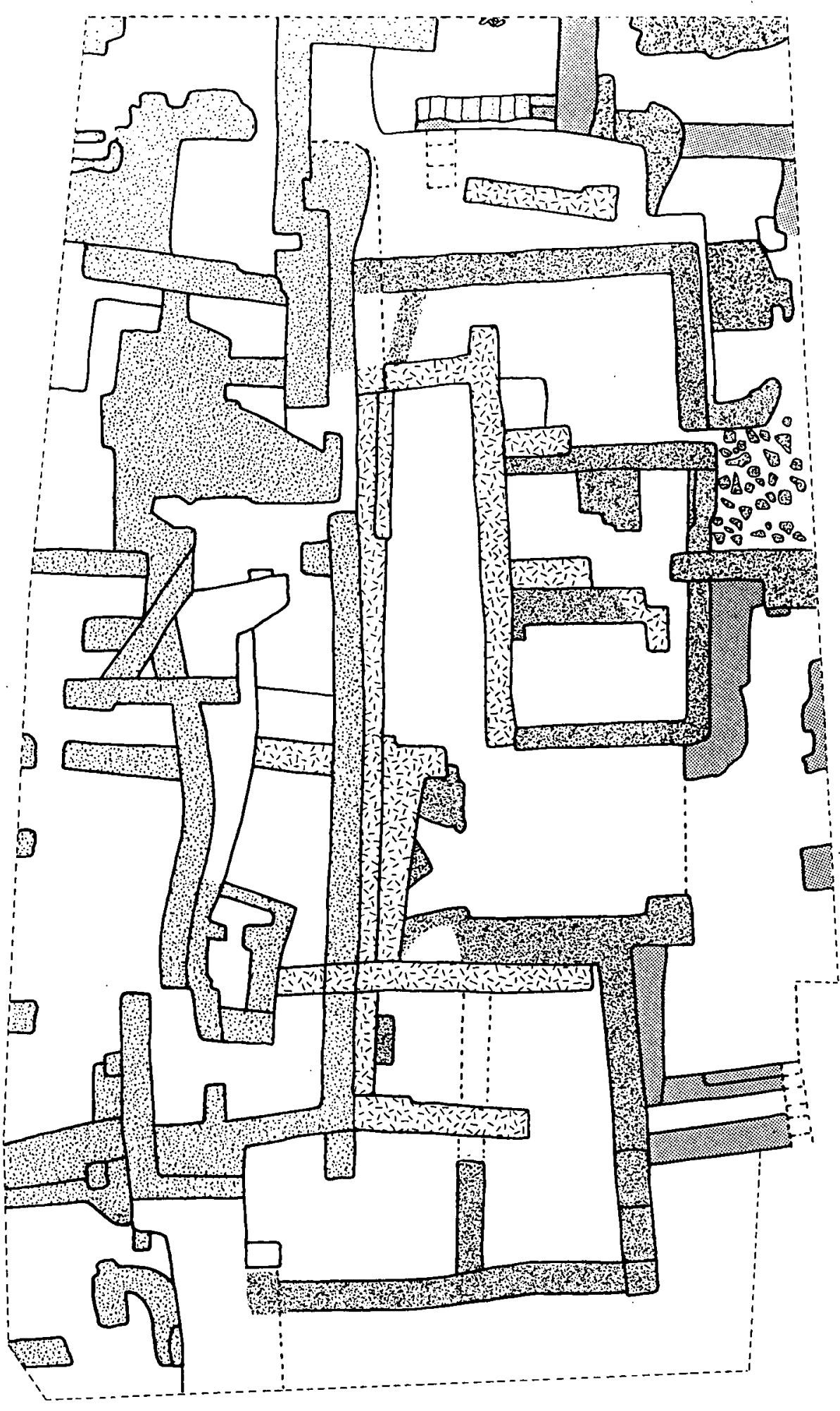

矛 

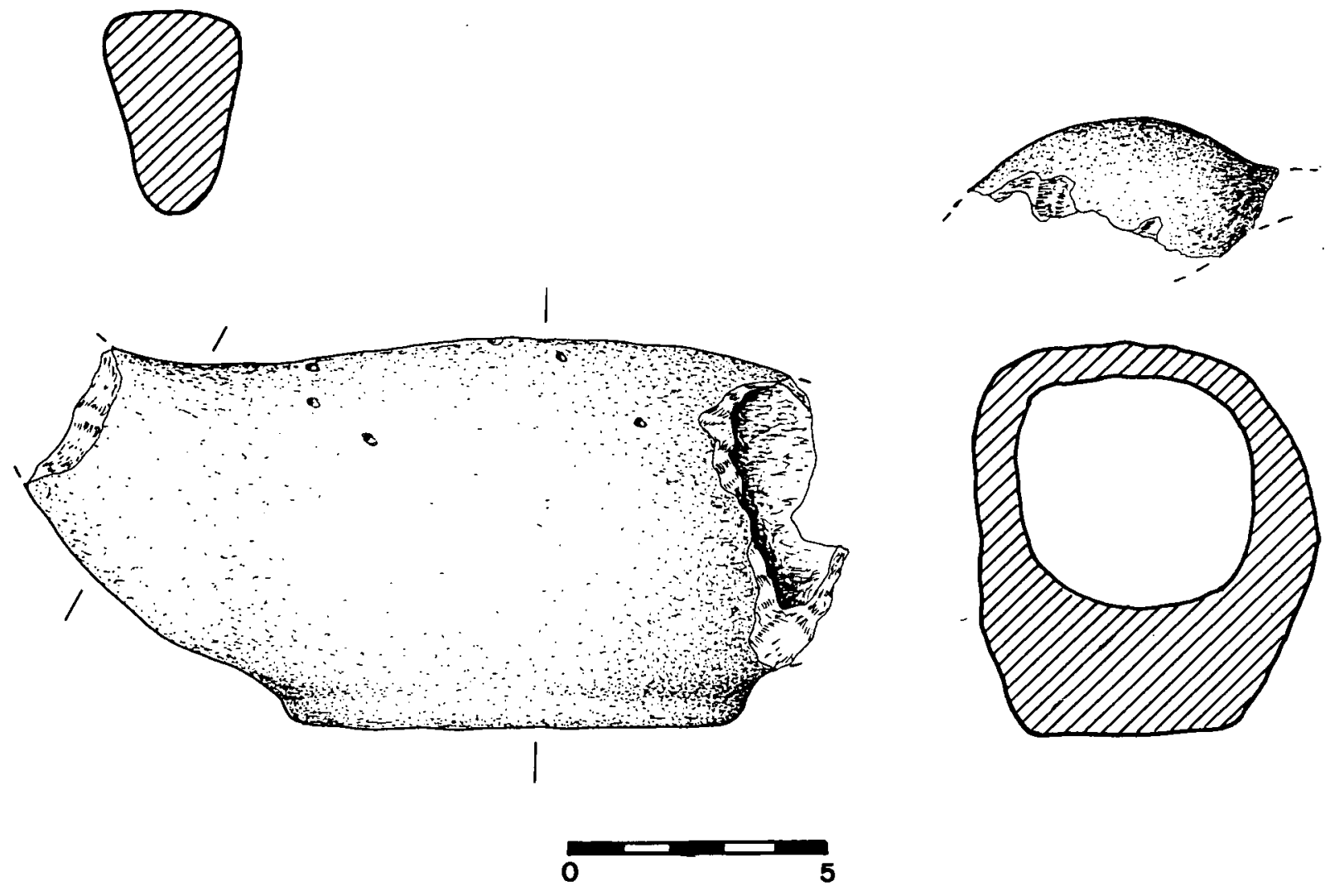

Figura 8 

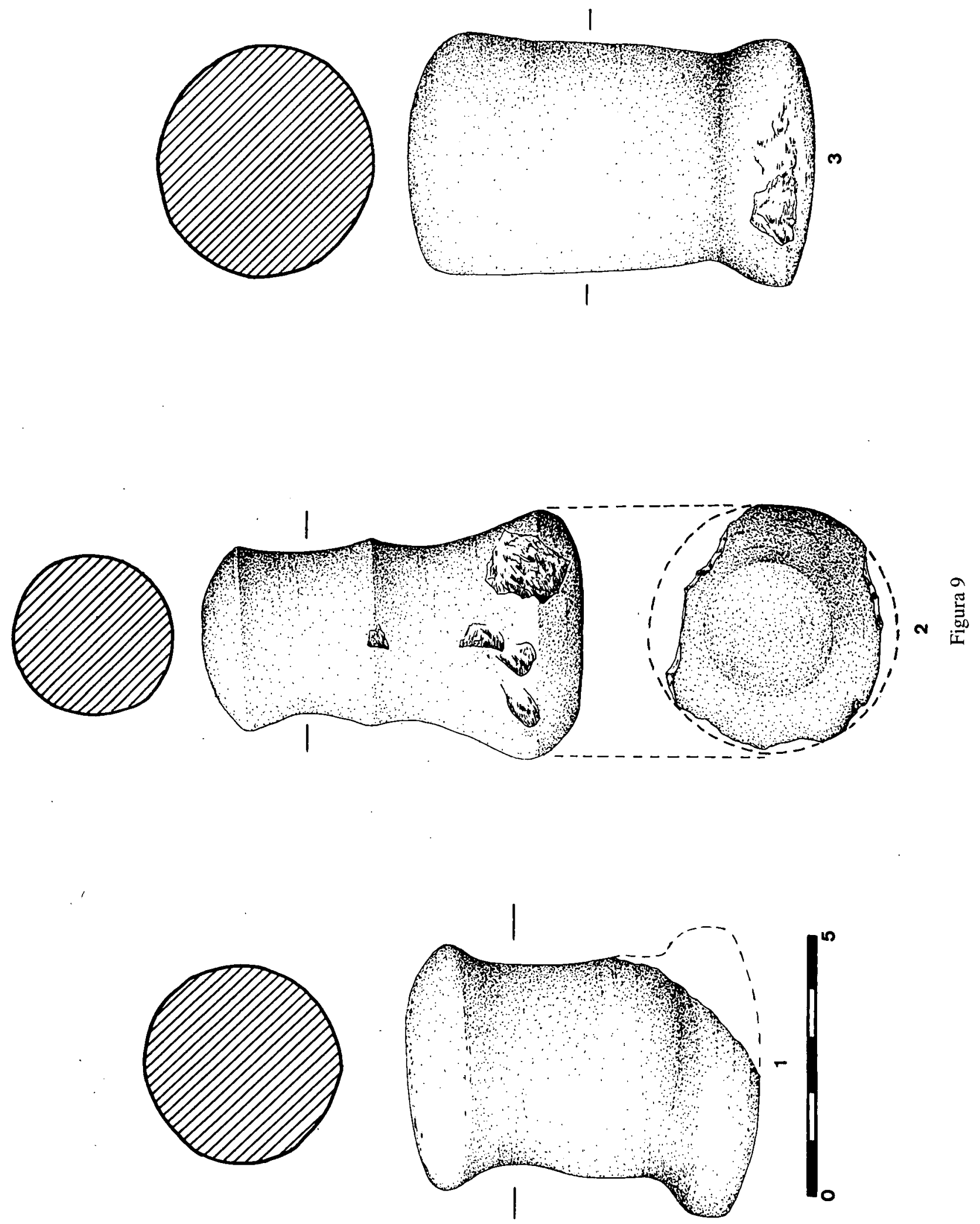

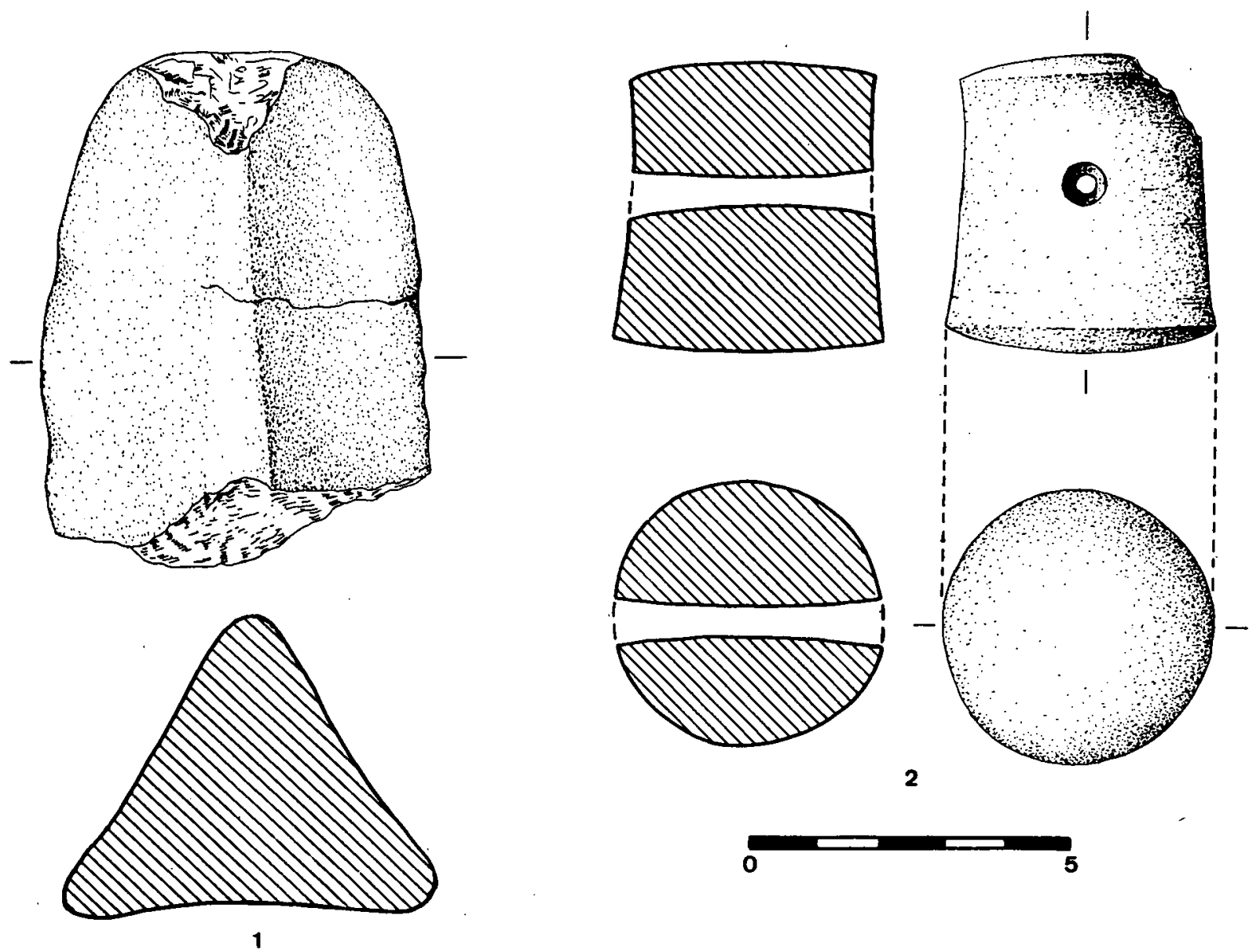

Figura 10 


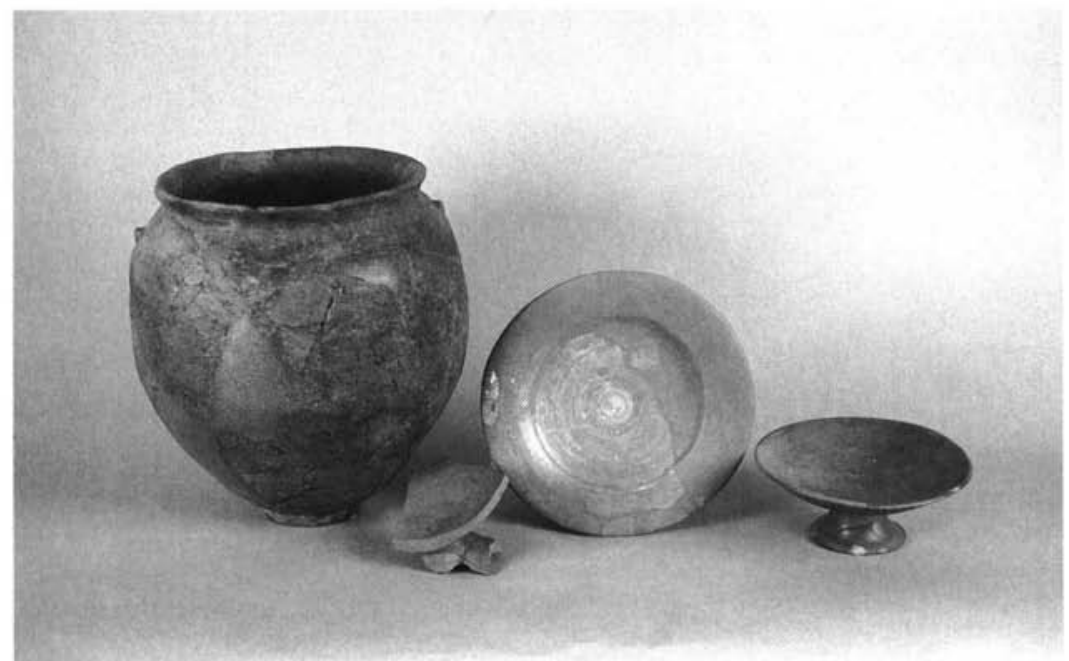

Lámina I

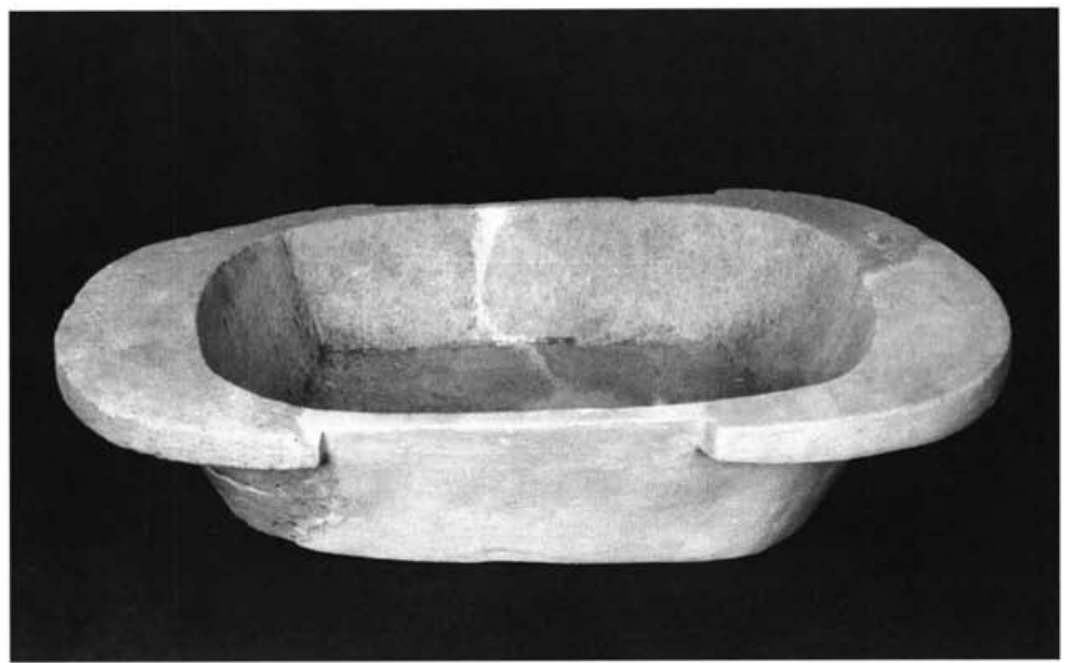

Lámina II 


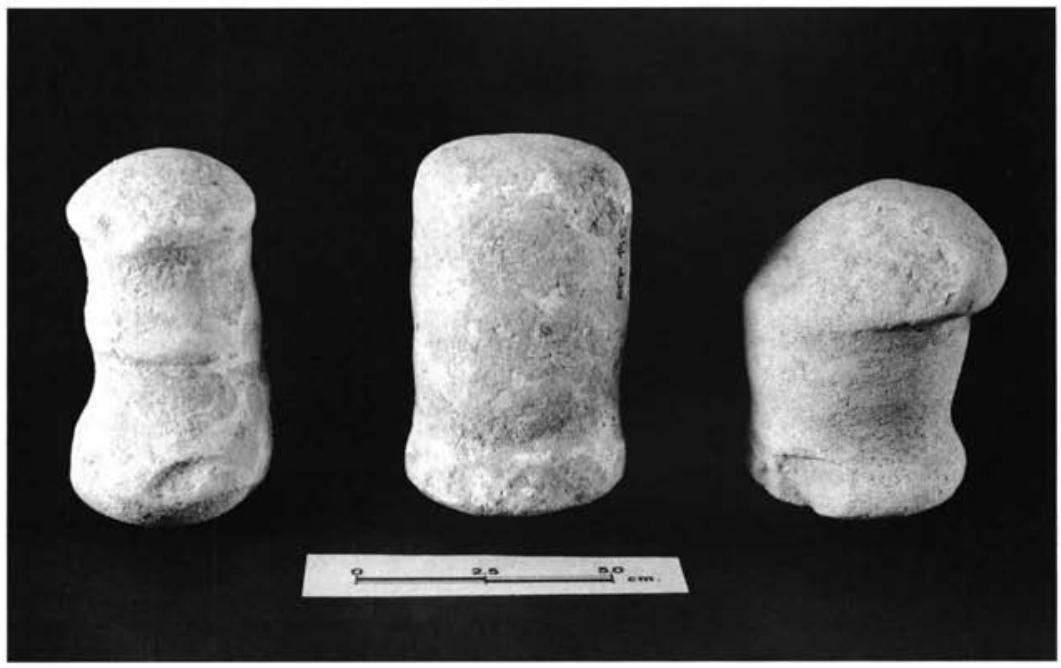

Lámina III 